\title{
Exploring the Influence of Granular Iron Additives on 1,1,1-Trichloroethane Reduction
}

\author{
David M. Cwiertny, Stephen J. Bransfield, Kenneth J.T. Livi, \\ D. Howard Fairbrother, and A. Lynn Roberts
}

\section{Supporting Information:}

29 Pages

10 Figures

3 Tables

Supporting Information describes all reagents used in the current study, the displacement plating procedure for reductant generation (see also Table S-1), the method for determination of the deposited additive mass via atomic absorption spectroscopy, and the protocol for control batch experiments. Also included are results of analyses conducted by X-ray photoelectron spectroscopy (Figure S-1), Auger electron spectroscopy (Figures S-2 and S-5), and scanning electron microscopy with energy dispersive X-ray spectroscopy (Figure S-3 and S-4). The relative reactivity of our bimetals at an additive loading of $\sim 13 \mu$ moles/g Fe is shown in Figure $\mathrm{S}-6$, and the influence of each bimetal on reactor $\mathrm{pH}$ is displayed in Figure S-7. Tables S-2 and S-3 present physical and electrochemical properties of the metal additives investigated that were compared to our experimental reactivity trend toward 1,1,1-TCA. Example time courses for 1,1,1-TCA reduction including model fits from nonlinear regression analyses are shown in Figures S-8, and data pertaining to 1,1,1-TCA product partitioning are presented in Figures S-9 and S-10. 


\section{Additional Experimental Details}

Reagents. 1,1,1-TCA (99.5\%, Aldrich) and 1,1-dichloroethane (1,1-DCA, 99\%, TCI America) were used as received. Gas standards of ethane, ethylene, and cis-2-butene (1000 ppm of each in $\mathrm{N}_{2}$ ) were acquired from Scott Specialty Gases. Buffer solutions of $50 \mathrm{mM}$ Tris

[tris(hydroxymethyl)aminomethane] in $0.1 \mathrm{M} \mathrm{NaCl}$ were prepared using deionized water (MilliQ Plus UV, Millipore), and were deoxygenated by sparging $(1 \mathrm{~h} / \mathrm{L})$ with $\mathrm{N}_{2}$. When necessary, solution $\mathrm{pH}$ was adjusted with $1 \mathrm{~N} \mathrm{HCl}$ or $\mathrm{NaOH}$ that had been deoxygenated by $\mathrm{N}_{2}$ sparging. All solutions were stored within an anaerobic chamber $\left(95 \% \mathrm{~N}_{2} / 5 \% \mathrm{H}_{2}\right.$ atmosphere) until use.

Electrolytic iron powder (100 mesh, Fisher) and the following metal salts were used to generate bimetallic reductants: potassium hexachloropalladate $\left(\mathrm{K}_{2} \mathrm{PdCl}_{6}, 98 \%\right.$, Aldrich), potassium hexachloroplatinate $\left(\mathrm{K}_{2} \mathrm{PtCl}_{6}, 99 \%\right.$, Aldrich), hydrogen tetrachloroaurate ( $\mathrm{HAuCl}_{4} \cdot 3 \mathrm{H}_{2} \mathrm{O}$, Alfa Aesar, $\left.99.999 \%\right)$, nickel chloride $\left(\mathrm{NiCl}_{2} \cdot 6 \mathrm{H}_{2} \mathrm{O}\right.$, Fisher), cobalt chloride $\left(\mathrm{CoCl}_{2} \cdot 6 \mathrm{H}_{2} \mathrm{O}, 98.4 \%\right.$, Fisher), and copper chloride $\left(\mathrm{CuCl}_{2} \cdot 2 \mathrm{H}_{2} \mathrm{O}\right.$, Fisher). Metal additive reactivity in the absence of iron was explored with powders of palladium (99.95\%, Alfa Aesar), platinum (99.9\%, Alfa Aesar), gold (99.96\%, Alfa Aesar), cobalt (99.8\%, Alfa Aesar), copper (electrolytic powder, Fisher), and nickel (laboratory grade, Fisher).

Displacement Plating Protocol for Bimetallic Reductant Generation. All reductants were synthesized specifically for this study; minor changes in our reductant preparation technique necessitated additional studies with $\mathrm{Cu} / \mathrm{Fe}$ so that results from $\mathrm{Cu} / \mathrm{Fe}$ systems could be directly compared to those obtained with other bimetals.

Bimetallic reductants were prepared as follows: within an anaerobic chamber, $2 \mathrm{~g}$ of electrolytic iron powder was weighed into a $250 \mathrm{~mL}$ Erlenmeyer flask. Prior to plating, the iron 
was washed with $\sim 40 \mathrm{~mL}$ of $1 \mathrm{M} \mathrm{HCl}$ for 10 minutes while stirring by hand, followed by three washes with deoxygenated, deionized water.

Displacement plating was accomplished by adding $25 \mathrm{~mL}$ of a metal additive salt solution in $0.01 \mathrm{~N} \mathrm{HCl}$ to the acid-washed and water-rinsed iron. The slurry was then stirred by hand for 5 minutes. Although not rigorously tested, limited studies suggested that this provided sufficient time for plating to proceed either to completion (for $\mathrm{Pd}, \mathrm{Pt}, \mathrm{Cu}$ and $\mathrm{Au}$ ) or to reach an apparent equilibrium (for $\mathrm{Ni}$ and $\mathrm{Co}$ ). To control the amount of additive deposited during plating, the metal salt concentration in the plating solution was varied (the concentrations employed for each additive are included in Table S-1).

After five minutes, the plating solution was separated from the reductant particles and was collected in $25 \mathrm{~mL}$ glass vials for analysis of residual additive. The plated iron was then rinsed three times with deoxygenated, deionized water; decants from these water washes were also collected for subsequent analyses. Exact volumes of all decants were determined gravimetrically. The plated iron was rinsed once with deoxygenated acetone, was removed from the glovebox, and was dried under $\mathrm{N}_{2}$ at $100^{\circ} \mathrm{C}$ for 30 minutes. Reductant particles were stored in sealed vials within the anaerobic chamber and were used within five hours of their preparation. 
Table S-1: Aqueous metal concentrations used in the preparation of bimetallic reductants and the corresponding deposited additive masses resulting from displacement plating. Values of deposited additive mass are presented both in $\mu$ moles of deposited metal additive/g Fe and percent of total reductant mass. Also included are the wavelengths at which AAS analyses were performed for each additive.

\begin{tabular}{lcccc}
\hline \hline $\begin{array}{c}\text { Metal } \\
\text { Additive }\end{array}$ & $\begin{array}{c}\text { Plating Solution } \\
\text { Concentrations } \\
(\mathbf{m M})\end{array}$ & $\begin{array}{c}\text { AAS } \\
\text { Wavelength } \\
(\mathbf{n m})\end{array}$ & $\begin{array}{c}\text { Deposited } \\
\text { Metal Masses } \\
(\mu \mathbf{\mu m o l e s} / \mathbf{g} \text { Fe) }\end{array}$ & $\begin{array}{c}\text { Deposited } \\
\text { Metal Masses } \\
(\% \text { mass })\end{array}$ \\
\hline Copper & $0.05-10$ & 324.8 & $0.63-125$ & $0.004-0.8$ \\
Nickel & $0.05-50$ & 232.0 & $0.031-56$ & $0.0002-0.3$ \\
Palladium & $0.005-4$ & 244.8 & $0.063-50$ & $0.0007-0.5$ \\
Platinum & $0.02-5$ & 265.9 & $0.25-63$ & $0.005-1.2$ \\
Gold & $0.01-10$ & 242.8 & $0.13-125$ & $0.003-2.5$ \\
Cobalt & $1-200$ & 240.7 & $0.15-270$ & $0.0009-1.6$ \\
\hline \hline
\end{tabular}


Atomic Absorption Spectroscopy. Prior to analysis with atomic absorption spectroscopy (AAS), plating solution decants and the collected water washes were acidified to a final concentration of $0.15 \mathrm{~N} \mathrm{HCl}$ within an anaerobic chamber. After one hour (to allow any colloidal particles to dissolve), the solutions were passed through a $0.22 \mu \mathrm{m}$ PVDF syringe-driven filter (Millipore) and were immediately analyzed using a Perkin Elmer Aanalyst 100 atomic absorption spectrometer. With the exception of nickel, all solutions were analyzed using an air-acetylene flame. Observed interferences from dissolved iron species required nickel solutions to be analyzed using a nitrous oxide-acetylene flame. The wavelength used for AAS analysis of each additive is provided in Table S-1.

Generally, we found our displacement plating procedure to yield plating efficiencies of $\sim 100 \%$ for $\mathrm{Pd}, \mathrm{Pt}, \mathrm{Cu}$ and $\mathrm{Au}$ (i.e., all metal ions initially present in solution were deposited onto iron as zero-valent metal). Consequently, all decants and water washes collected for these additives contained metal concentrations below the detection limits of AAS. Although Ni and Co did not exhibit $100 \%$ plating efficiency, we found that the concentrations of these metals in their final water washes were also below the detection limits of AAS. Accordingly, this indicates that the $\mathrm{Ni}$ and $\mathrm{Co}$ that had not been reductively deposited onto iron as $\mathrm{Ni}^{0}$ and $\mathrm{Co}^{0}$ had been quantitatively removed from the reductant surface by the conclusion of our washing steps. Experiments with Unamended Iron and Metal Additives in the Absence of Iron. Batch experiments to investigate 1,1,1-TCA reduction by unamended iron were carried out under conditions identical to those used for experiments with bimetallic reductants. To simulate the conditions of displacement plating, unamended granular iron was acid-washed with $1 \mathrm{~N} \mathrm{HCl}$ for $10 \mathrm{~min}$, followed by a $5 \mathrm{~min}$ wash with $0.01 \mathrm{~N} \mathrm{HCl}$. 
Experiments with 1,1,1-TCA were also conducted with powders of each metal additive in the absence of iron. These reactions were conducted at a reductant mass loading of $0.94 \mathrm{~g} / \mathrm{L}$. Metal powders were acid-washed with $1 \mathrm{~N} \mathrm{HCl}$ for 10 minutes prior to use. As exposure to $\mathrm{H}_{2}(\mathrm{~g})$ in the glovebox atmosphere could potentially contribute to metal reactivity (particularly for Pd), these reactors were constructed outside the glovebox using deoxygenated $\left(\mathrm{N}_{2}\right.$-sparged $)$ solutions. 


\section{Bimetallic Reductant Characterization}

X-ray Photoelectron Spectroscopy. Representative X-ray photoelectron spectra (XPS) for most of the bimetallic reductants examined in this study are shown in Figure S-1. An XP spectrum for $\mathrm{Cu} / \mathrm{Fe}$ is not shown, as it was similar to that presented in our earlier work with $\mathrm{Cu} / \mathrm{Fe}$ reductants (1). Results of XPS analyses were consistent with the presence of all additives in a metallic oxidation state; spectral features characteristic of other oxidation states were not observed. Auger Electron Spectroscopy. The two-dimensional additive surface coverage was determined from Auger electron spectroscopy (AES). Metal additive surface coverages (reported as percent) were calculated by normalizing the atomic concentration of the metal additive detected by AES by the total metal concentration (Additive $+\mathrm{Fe}$ ) detected by AES (eq S-1)

$$
\% \text { Additive }=[\text { Additive } /(\text { Additive }+\mathrm{Fe})] \times 100
$$

Accordingly, the metal additive surface coverage (which represents a mole fraction concentration) can vary from $0 \%$ (unamended iron) to $100 \%$ (iron completely buried by a thick additive overlayer). This approach provides a convenient metric of metal additive surface coverage and is identical to that utilized in our earlier work with $\mathrm{Cu} / \mathrm{Fe}$ reductants (1).

Values of additive surface coverage are plotted as a function of deposited additive mass (determined from atomic absorption spectroscopy) in Figure S-2. For the additives shown, increasing the mass of deposited additive tended to produce an initial increase in additive twodimensional surface coverage followed by a plateau in coverage at higher loadings. We note that AES surface coverages for $\mathrm{Pt} / \mathrm{Fe}$ and $\mathrm{Au} / \mathrm{Fe}$ reductants are not reported, as spectral features associated with other elements (e.g., adventitious oxygen and carbon, residual chlorine or the underlying iron) obscured the characteristic AES peaks of these metals. 
For the metal additives amenable to AES analysis, some differences in two-dimensional surface coverage are revealed in Figure S-2. While the dependence of surface coverage on deposited additive mass was comparable for $\mathrm{Pd}$ and $\mathrm{Cu}$, values of $\mathrm{Ni}$ and $\mathrm{Co}$ surface coverage were much lower at similar values of deposited mass.

These differences are not entirely understood, although they may be related to the behavior of our bimetals during sample preparation for AES analysis. During sample transport from the anaerobic chamber in which reductants were prepared to the AES analytical chamber, bimetals were exposed to the ambient atmosphere. As Ni and Co possess reduction potentials that are much lower than those of $\mathrm{Pd}$ and $\mathrm{Cu}, \mathrm{Ni}$ and $\mathrm{Co}$ are considerably more susceptible to oxidation by atmospheric dioxygen. Such additive-dependent processes complicate quantitative comparison of AES surface coverages between different reductants, and may be responsible for the range of values reported in Figure S-2. Consequently, we maintain that values of deposited additive mass from AAS are more appropriate as a basis for comparing the reactivity of a suite of iron-based bimetals.

Elemental Mapping of Iron-Based Bimetallic Reductants. Figure S-3a reveals the backscattered electron (BSE) image from scanning electron microscopy (SEM) for Pd/Fe reductants with $\sim 50$ $\mu$ moles $\mathrm{Pd} / \mathrm{g}$ Fe, while the corresponding Pd $L \alpha$ EDS map is shown in Figure S-3b (bright regions indicate relatively high concentrations of Pd). As is clearly revealed in the elemental maps, the Pd overlayer was not uniformly distributed on the iron surface, with localized regions evident in which Pd deposition was enhanced (circled; EDS spectrum shown in Figure S-3c) as well as other regions with no discernible Pd (enclosed in square; EDS spectrum shown in Figure S-3d).

Similar overlayers were observed for $\mathrm{Au} / \mathrm{Fe}$ and $\mathrm{Pt} / \mathrm{Fe}$ reductants (Figure S-4). As 
observed for the cross-sectional elemental maps of $\mathrm{Pd} / \mathrm{Fe}$, localized regions of elevated additive deposition (bright areas on elemental maps) and regions with little or no additive deposition are clearly evident.

Figure S-5 shows a secondary electron image (SED) and elemental maps for Fe and $\mathrm{Ni}$ collected using scanning Auger electron spectroscopy performed on $\mathrm{Ni} / \mathrm{Fe}$ reductants. This particular Ni/Fe reductant possessed an additive loading (40 $\mu$ moles Ni/g Fe) comparable to those of the $\mathrm{Pd} / \mathrm{Fe}$ and $\mathrm{Pt} / \mathrm{Fe}$ reductants considered in Figures S-3 and $\mathrm{S}-4$, respectively. While SEM-EDS elemental mapping of these $\mathrm{Ni} / \mathrm{Fe}$ reductants did not reveal the presence of $\mathrm{Ni}$ on the particle surface, Ni was clearly observed in the near surface region via elemental mapping with AES. Furthermore, the AES elemental map revealed that Ni was unevenly distributed on the surface of these iron grains; recall that non-homogeneous distributions of $\mathrm{Pd}, \mathrm{Cu}, \mathrm{Au}$ and $\mathrm{Pt}$ on iron were also observed with SEM-EDS elemental mapping. Nevertheless, our inability to identify $\mathrm{Ni}$ and $\mathrm{Co}$ on bimetallic reductants via cross-sectional SEM-EDS analyses suggests that the additive overlayer on these bimetals may be different from those of the other four reductants investigated.

We hypothesize that such differences could be related to the reduction potentials of the metals investigated. $\mathrm{Pd}, \mathrm{Pt}, \mathrm{Au}$ and $\mathrm{Cu}$ generally possess large, positive reduction potentials versus the standard hydrogen electrode, while the reduction potentials of $\mathrm{Ni}$ and $\mathrm{Co}$ are negative. The thermodynamic driving force for deposition is greatest, therefore, for $\mathrm{Pd}, \mathrm{Pt}, \mathrm{Au}$, and $\mathrm{Cu}$, and this may ultimately influence the nature of the overlayer resulting from displacement plating. 

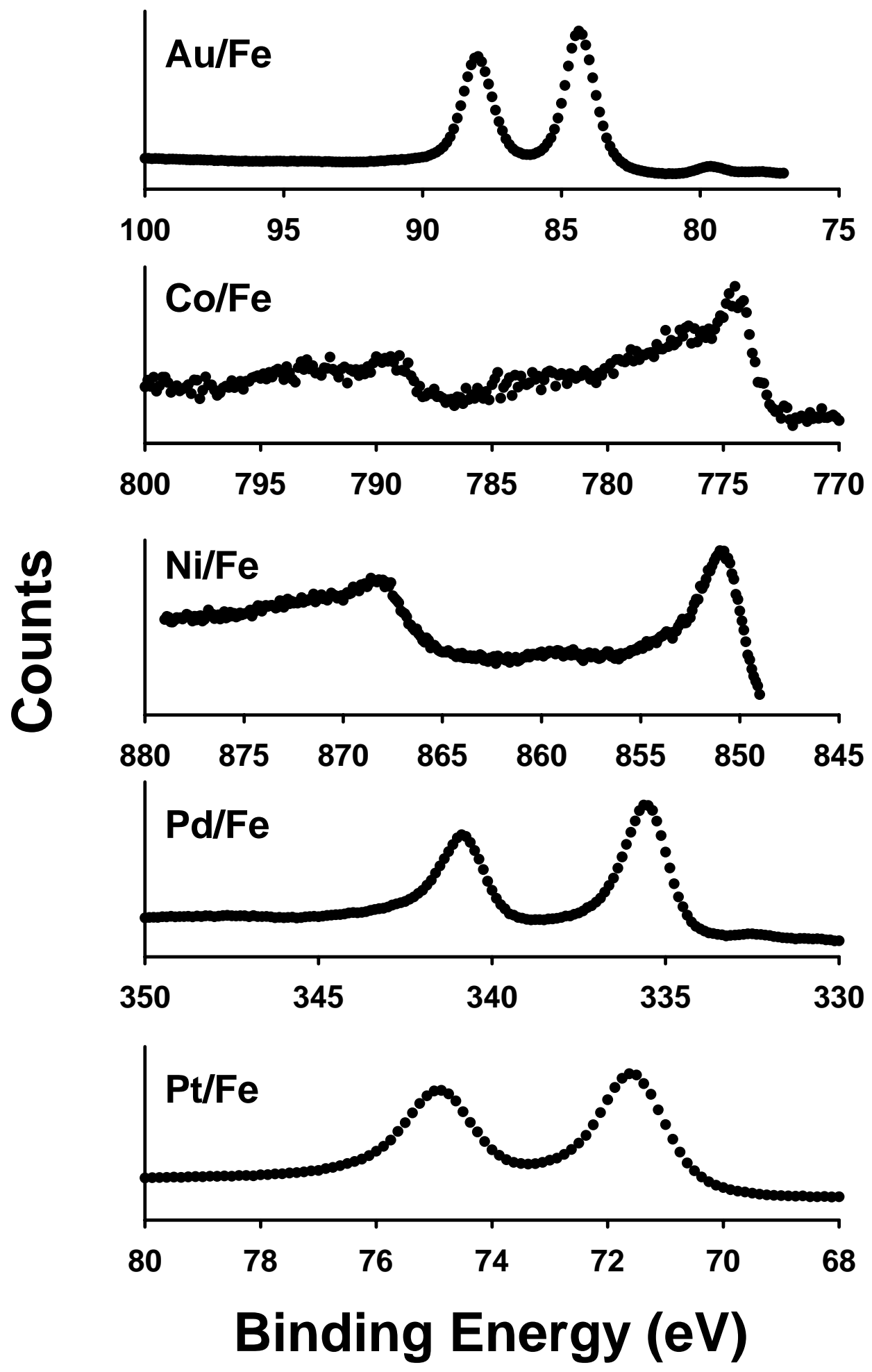

Figure S-1: Typical XP spectra obtained for $\mathrm{Au} / \mathrm{Fe}, \mathrm{Co} / \mathrm{Fe}, \mathrm{Ni} / \mathrm{Fe}, \mathrm{Pd} / \mathrm{Fe}$ and $\mathrm{Pt} / \mathrm{Fe}$ reductants investigated in this study. For each reductant, only binding energies that revealed characteristic line shapes of the deposited metal additive are shown. Spectra for $\mathrm{Cu} / \mathrm{Fe}$ were identical to those observed in our earlier work with $\mathrm{Cu} / \mathrm{Fe}$ reductants (1). 


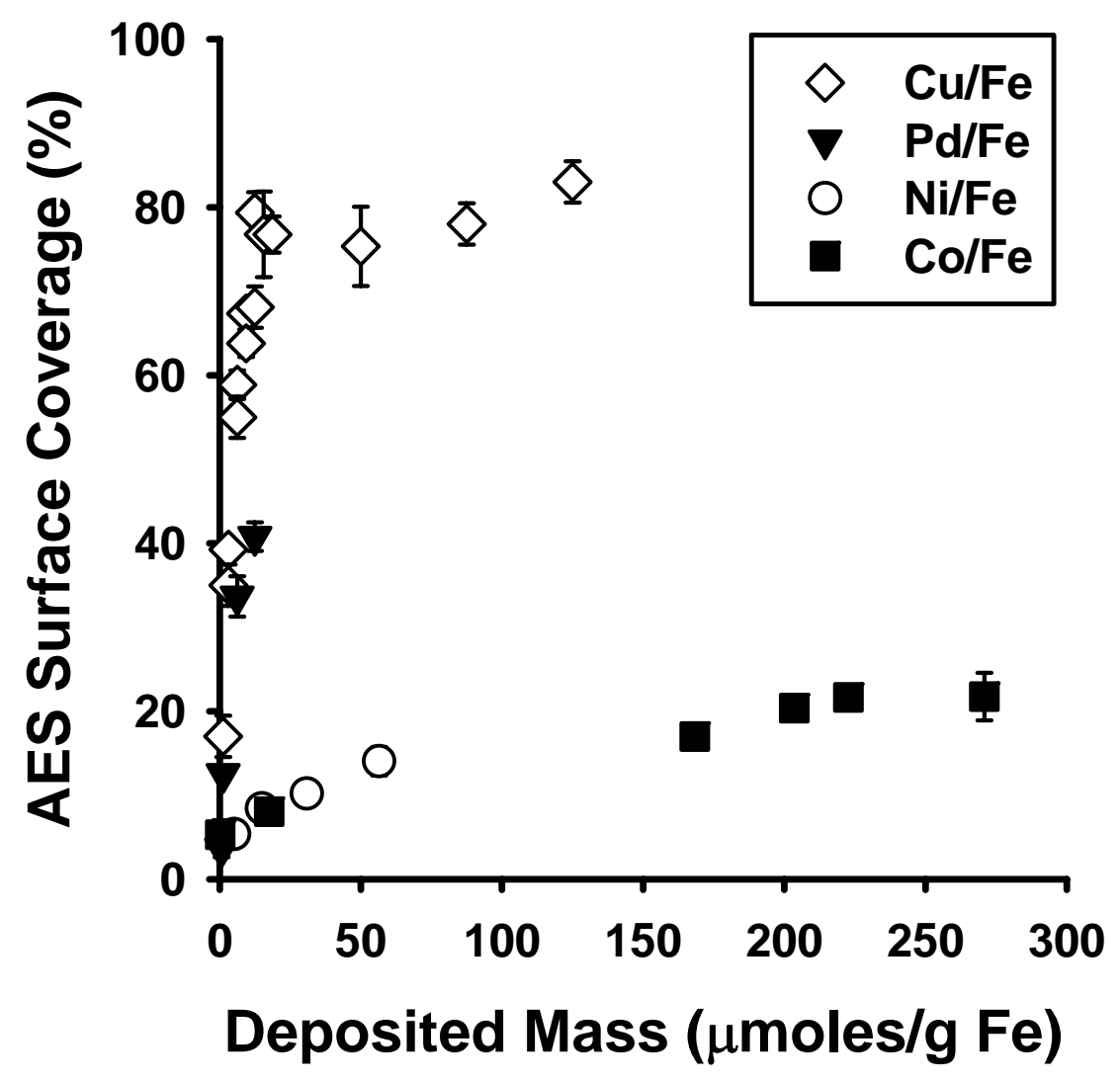

Figure S-2: Plots of two-dimensional additive surface coverage (as determined by Auger electron spectroscopy) as a function of deposited additive mass (obtained from atomic absorption spectroscopy) for $\mathrm{Cu} / \mathrm{Fe}, \mathrm{Pd} / \mathrm{Fe}, \mathrm{Ni} / \mathrm{Fe}$ and $\mathrm{Co} / \mathrm{Fe}$ systems. Measurements of AES twodimensional surface coverage were made in triplicate, and uncertainties represent one standard deviation. 
a)

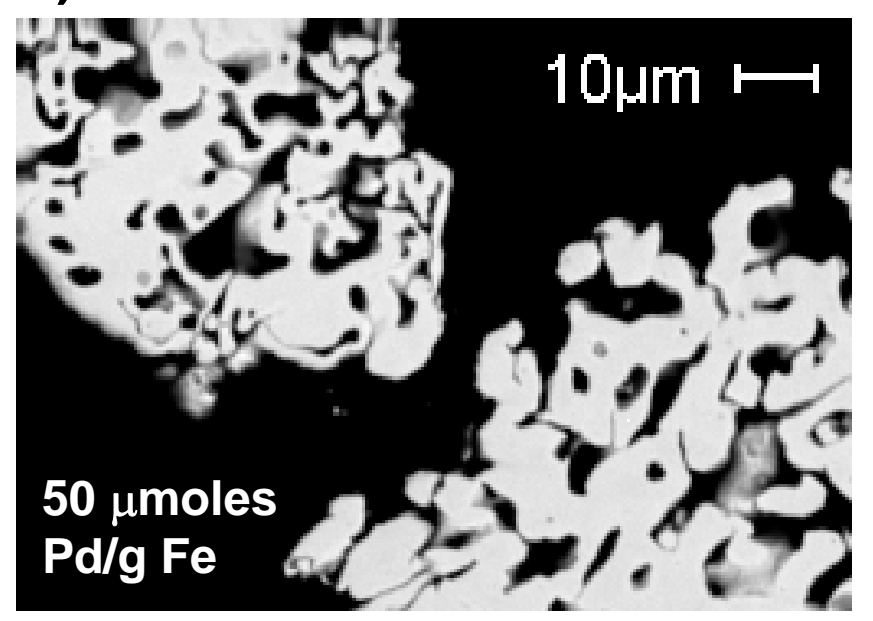

c)

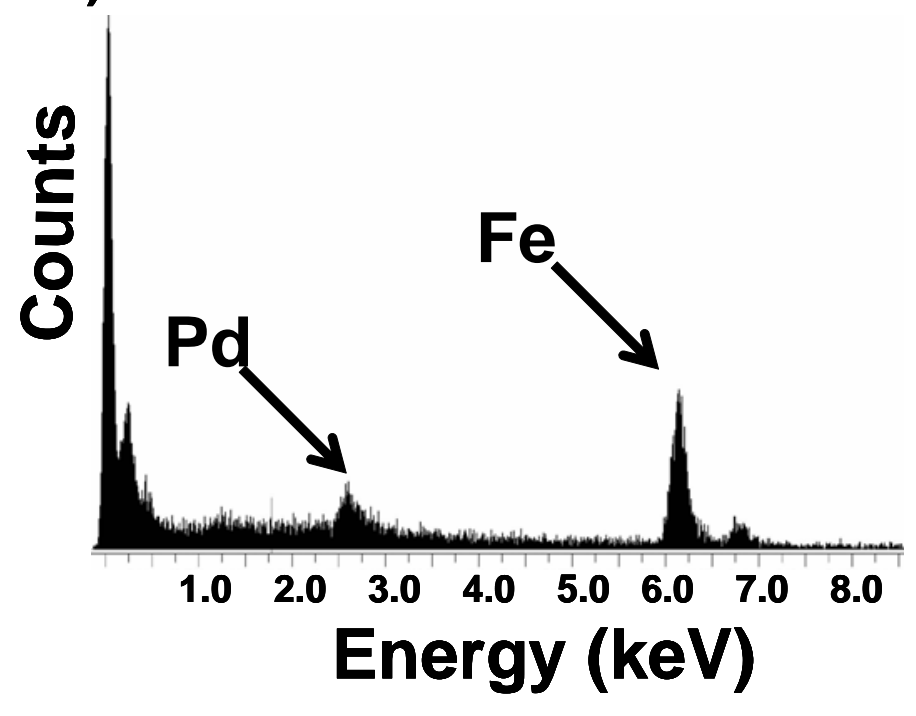

b)

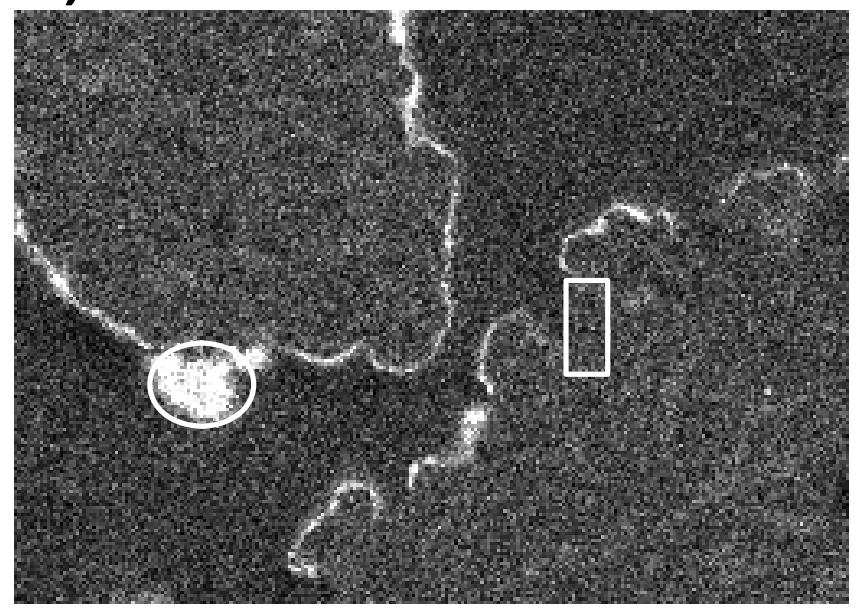

d)

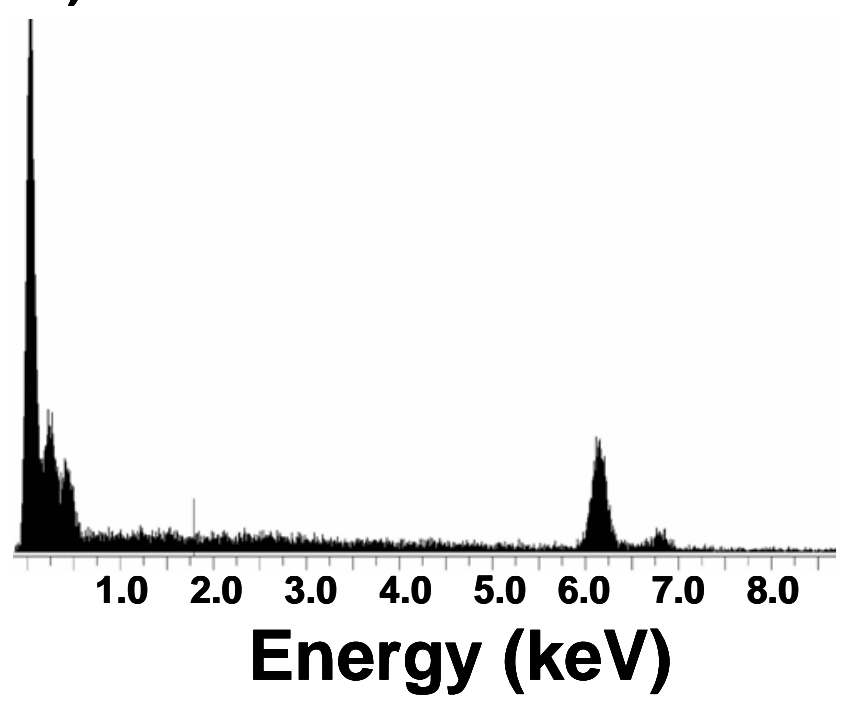

Figure S-3: (a) Cross-sectional backscattered electron image of two $\mathrm{Pd} / \mathrm{Fe}$ reductant grains containing approximately $50 \mu$ moles of deposited $\mathrm{Pd} / \mathrm{g}$ Fe. (b) Corresponding $\operatorname{Pd} L \alpha$ EDS elemental map of the reductants shown in (a). Bright regions indicate areas of relatively high $\mathrm{Pd}$ concentration. Elemental maps clearly reveal regions of both thick (circled) and thin to nonexistent (enclosed in square) Pd deposits on the iron surface. EDS spectra collected from within these regions are shown in (c) and (d), respectively. 

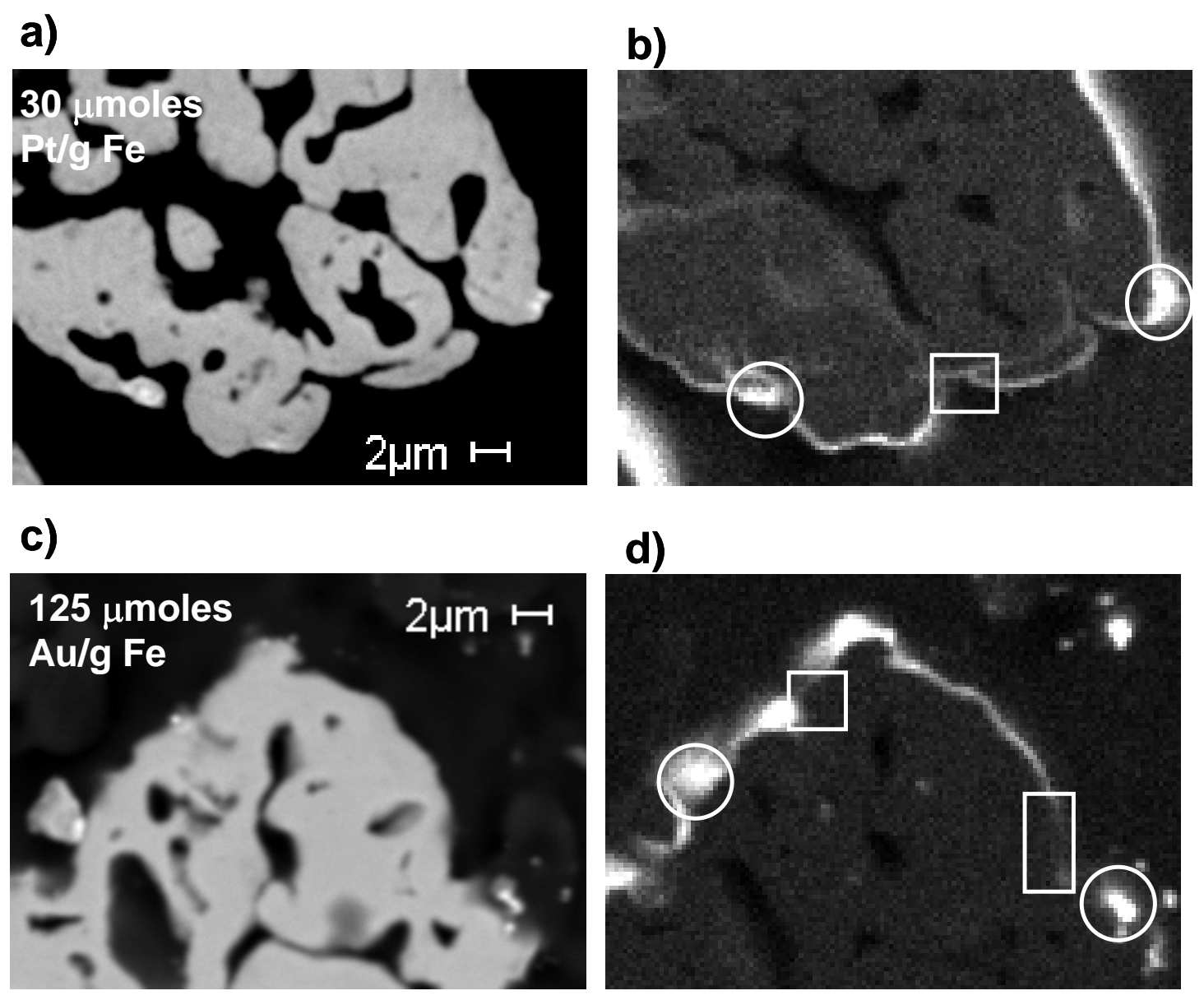

Figure S-4: Cross-sectional backscattered electron image and corresponding elemental maps for $\mathrm{Pt} / \mathrm{Fe}$ ((a) and (b), respectively) and $\mathrm{Au} / \mathrm{Fe}$ ((c) and (d), respectively) reductants. $\mathrm{Pt} / \mathrm{Fe}$ reductants contained $30 \mu$ moles deposited Pt/g Fe, while Au/Fe reductants contained $125 \mu$ moles deposited $\mathrm{Au} / \mathrm{g} \mathrm{Fe}$. Bright regions on elemental maps indicate areas of relatively high metal additive surface concentration. As was observed for $\mathrm{Pd} / \mathrm{Fe}$ in Figure S-3, elemental maps of each bimetal reveal regions of both thick (circles) and thin to nonexistent (enclosed in squares) additive deposits on the iron surface. 


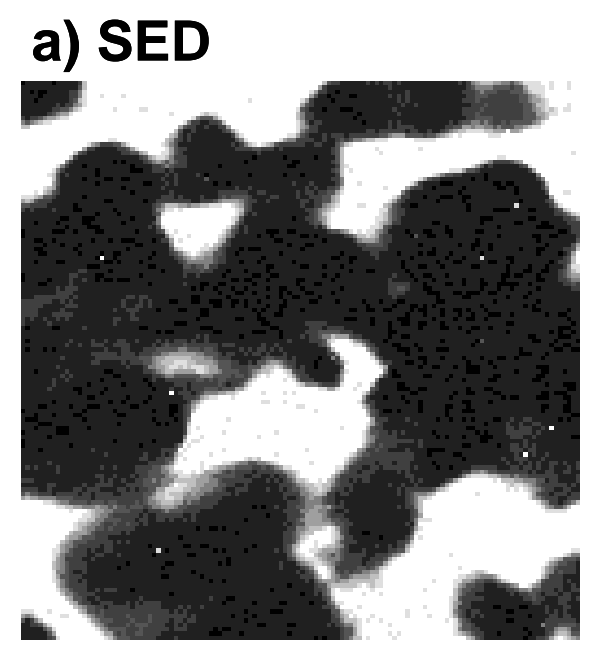

\section{b) $\mathrm{Fe}$}

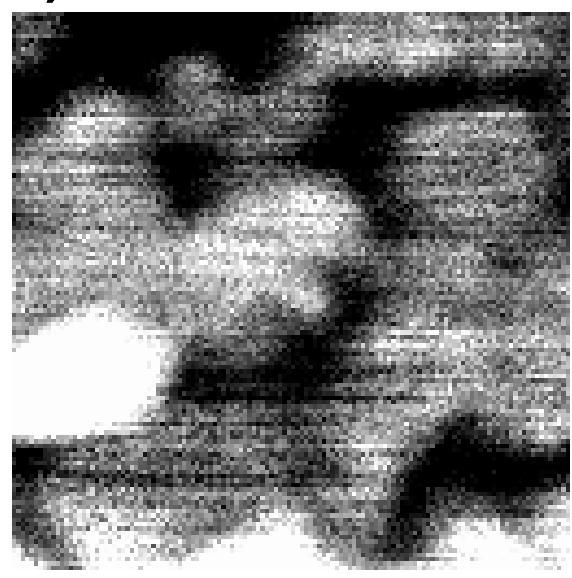

\section{c) $\mathrm{Ni}$}

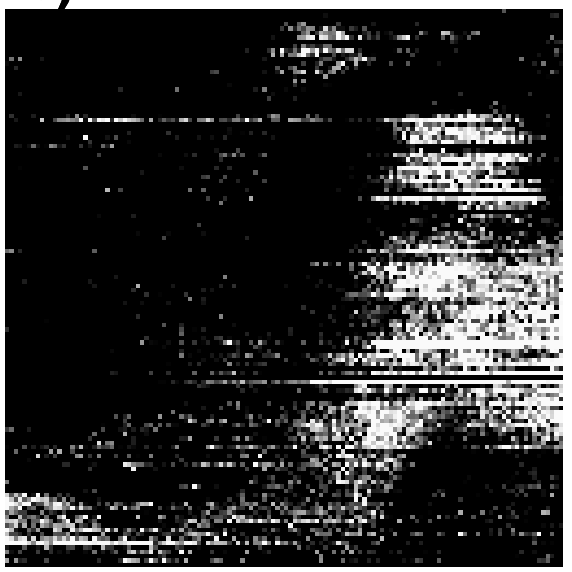

Figure S-5: (a) Secondary electron image (SED) and (b) iron and (c) nickel elemental maps collected with Auger electron spectroscopy for $\mathrm{Ni} / \mathrm{Fe}$ reductants containing $40 \mu$ moles deposited $\mathrm{Ni} / \mathrm{g}$ Fe. The area shown has dimensions of $250 \times 250 \mu \mathrm{m}$. In the SED, dark regions are indicative of the location of $\mathrm{Ni} / \mathrm{Fe}$ grains. In the elemental maps, bright regions correspond to higher concentrations of the element in question. 


\section{Relative Bimetallic Reactivity and Calculated Rate Enhancements}

Plots of aqueous 1,1,1-TCA concentration as a function of time are shown in Figure S-6a for each bimetal with an additive loading of $\sim 13 \mu$ moles/g Fe. Data collected in an unamended iron batch system are included for comparison. In all cases, concentration data for 1,1,1-TCA revealed good adherence to exponential decay (shown as dashed lines).

The magnitude of rate enhancement provided by each reductant was calculated by normalizing the pseudo-first-order rate constant for 1,1,1-TCA reduction $\left(k_{\mathrm{obs}}\right)$ in each bimetallic system by the $k_{\text {obs }}$ value measured with unamended iron. Calculated rate enhancements for each reductant at an additive loading of $\sim 13 \mu$ moles/g Fe are shown in Figure S- $6 \mathrm{~b}$. This trend in reductant reactivity was generally consistent over the entire range of additive loadings considered in this study (compare to Figure 1 of the main text). 
a)

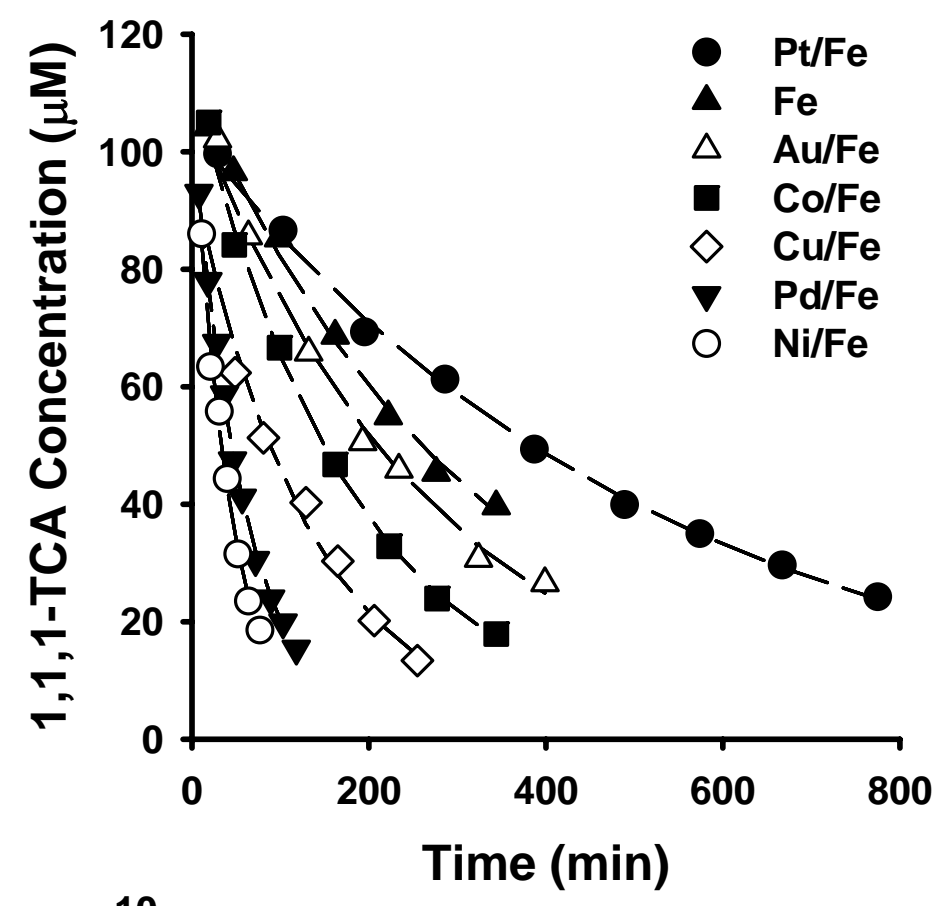

b)

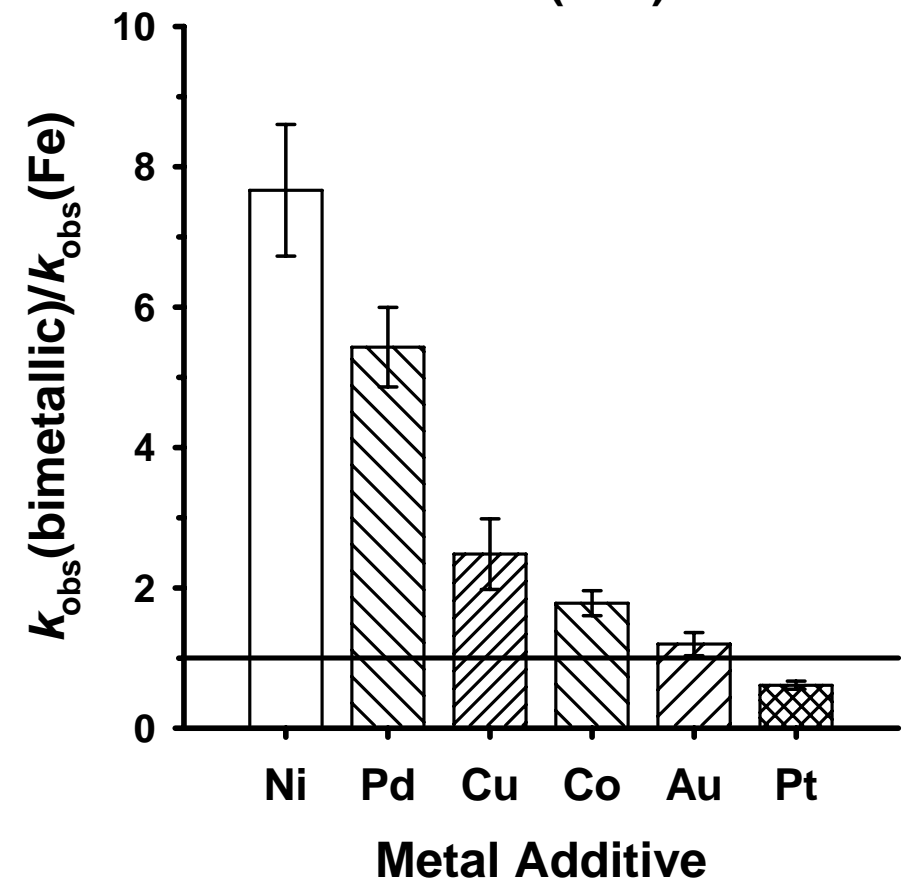

Figure S-6: (a) Plots of 1,1,1-TCA concentration as a function of time for bimetallic reductants with a deposited additive mass of $\sim 13 \mu$ moles/g Fe. Data for 1,1,1-TCA reduction by unamended granular iron are included for comparison. Dashed lines represent exponential decay model fits to the experimental data. Batch reactors contained $50 \mathrm{mM}$ Tris $/ 0.1 \mathrm{M} \mathrm{NaCl}$ at an initial $\mathrm{pH}$ of 7.20 and a reductant loading of $1.6 \mathrm{~g} / \mathrm{L}$. (b) Calculated magnitude of rate enhancement provided by bimetallic reductants with an additive loading of $\sim 13 \mu$ moles $/ \mathrm{g} \mathrm{Fe}$. 


\section{Influence of Reactor pH on Bimetal Reactivity}

As iron reactivity decreases with increasing $\mathrm{pH}(2,3)$, the influence of each additive on reactor $\mathrm{pH}$ merits consideration. Recall that the initial $\mathrm{pH}$ in all reductant systems was 7.20. The values of system $\mathrm{pH}$ measured at the conclusion of the reaction with 1,1,1-TCA (approximately $\sim 30 \mathrm{~h}$ after reactor assembly) are shown as a function of deposited additive mass in Figure S-7. For comparison, the final system $\mathrm{pH}$ measured in an unamended iron system is also provided (solid horizontal line). As was observed in our earlier work investigating alkyl polyhalide reduction by granular iron (3), this final $\mathrm{pH}$ measurement (taken at $\mathrm{t} \sim 30 \mathrm{~h}$ ) was approximately equal to the reactor $\mathrm{pH}$ during the reaction between 1,1,1-TCA and all reductants; the majority of the $\mathrm{pH}$ increase in our bimetallic systems occurred over the $24 \mathrm{~h}$ prior to the addition of 1,1,1TCA to our reactors.

While the $\mathrm{pH}$ in $\mathrm{Ni} / \mathrm{Fe}, \mathrm{Cu} / \mathrm{Fe}, \mathrm{Co} / \mathrm{Fe}$ and $\mathrm{Au} / \mathrm{Fe}$ systems increased by $\sim 0.2 \mathrm{pH}$ units over the lifetime of the reactor, the magnitude of this increase did not vary as a function of these additives' loadings, nor was it substantially different from the $\mathrm{pH}$ change measured in unamended iron systems. The $\mathrm{pH}$ increases measured in $\mathrm{Pt} / \mathrm{Fe}$ and $\mathrm{Pd} / \mathrm{Fe}$ systems, on the other hand, were greater and tended to increase, at least initially, with Pt and Pd loading (producing a maximum increase of $0.5 \mathrm{pH}$ units in these systems). While this elevated $\mathrm{pH}$ may have contributed to the depressed $k_{\text {obs }}$ values measured with $\mathrm{Pt} / \mathrm{Fe}$ reductants, the final $\mathrm{pH}$ in these systems was nearly invariant for Pt loadings in excess of $1.25 \mu$ moles Pt/g Fe (Figure S-7). We conclude that the two-fold decrease in $k_{\mathrm{obs}}$ values over this same range of Pt loadings (see Figure 1 of main text) indicates that increases in system $\mathrm{pH}$ cannot entirely account for the inhibition of 1,1,1-TCA reduction in $\mathrm{Pt} / \mathrm{Fe}$ systems. 


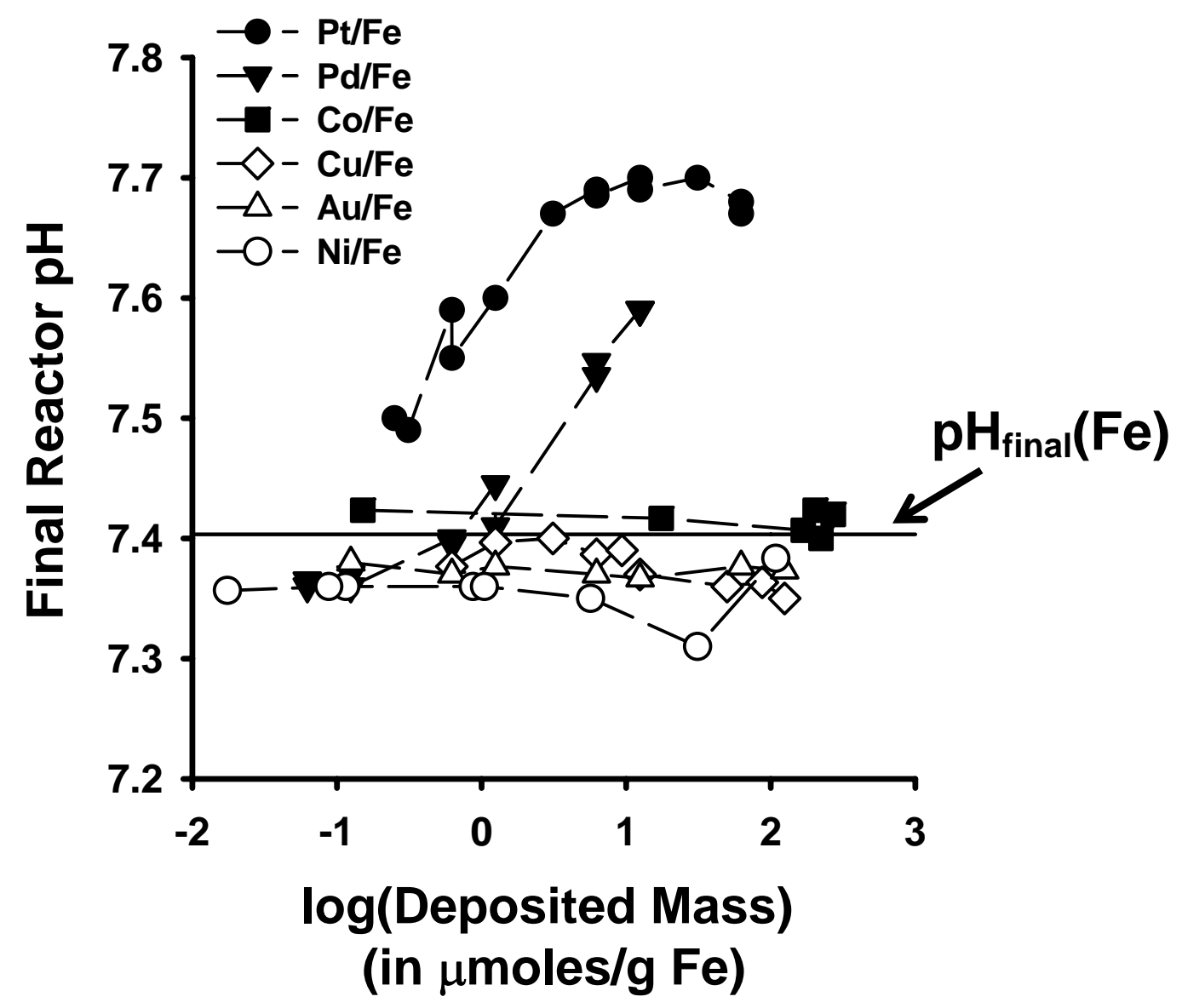

Figure S-7: Final reactor $\mathrm{pH}$ (measured at the conclusion of the reaction time course with 1,1,1TCA at $t \sim 30 \mathrm{~h}$ ) as a function of deposited additive mass on a logarithmic scale. As indicated, the solid horizontal line represents the final $\mathrm{pH}$ measured in reactors with unamended granular iron. All reactors contained $50 \mathrm{mM}$ Tris/ $0.1 \mathrm{M} \mathrm{NaCl}$ with an initial $\mathrm{pH}$ of 7.20. 


\section{Relating the Reactivity of Bimetallic Reductant to Metal Additive Properties}

For the reduction of 1,1,1-TCA, we observed the following trend in bimetal reactivity:

$\mathrm{Ni} / \mathrm{Fe} \approx \mathrm{Pd} / \mathrm{Fe}>\mathrm{Cu} / \mathrm{Fe}>\mathrm{Co} / \mathrm{Fe}>\mathrm{Au} / \mathrm{Fe} \approx$ unamended iron $>\mathrm{Pt} / \mathrm{Fe}$. Comparison of this trend to various physical and electrochemical properties of the metal additives investigated, such as those shown in Table S-2, revealed no apparent correlation.

A strong correlation was observed, however, when values of $k_{\text {obs }}$ for 1,1,1-TCA reduction were compared to values of the relative partial molar enthalpy for an infinitely dilute solution of hydrogen within the lattice of each metal additive $\left(\Delta \mathrm{H}_{\mathrm{H}}{ }^{\infty}\right)$. Values of $\Delta \mathrm{H}_{\mathrm{H}}{ }^{\infty}$ for each of the metal additives considered are shown in Table S-3. These value represent experimentally measured enthalpies that were tabulated by Gallagher and Oates (4). Also included in Table S-3 are the range of temperatures over which each $\Delta \mathrm{H}_{\mathrm{H}}{ }^{\infty}$ value was experimentally determined in the references cited by Gallagher and Oates. 
Table S-2: Physical and electrochemical properties of the additives investigated that might be expected to exert an influence on the reactivity of bimetallic reductants. With the exception of $\mathrm{M}-\mathrm{H}_{\mathrm{ads}}$ bond enthalpies, all values were taken from ref 5.

\begin{tabular}{|c|c|c|c|c|c|c|c|c|}
\hline $\begin{array}{c}\text { Metal } \\
\text { Additive }\end{array}$ & $\begin{array}{l}\text { Atomic } \\
\text { Weight } \\
\text { (g/mol) }\end{array}$ & $\begin{array}{l}\text { Density } \\
\left(\mathrm{g} / \mathrm{cm}^{3}\right)\end{array}$ & $\begin{array}{l}\text { Crystal } \\
\text { Structure }\end{array}$ & $\begin{array}{c}\text { Lattice } \\
\text { Constant } \\
(\AA) \\
(@ 298 \mathrm{~K}) \\
\end{array}$ & $\begin{array}{c}\text { Electrical } \\
\text { Resistivity } \\
\left(10^{-8} \Omega \mathrm{m}\right) \\
(@ 298 \mathrm{~K}) \\
\end{array}$ & $\begin{array}{c}\text { Work } \\
\text { Function } \\
(\mathrm{eV})\end{array}$ & $\begin{array}{c}\text { Standard } \\
\text { Reduction } \\
\text { Potential } \\
\text { (V vs. NHE) }\end{array}$ & $\begin{array}{c}\text { M-H } \text { ads } \\
\text { Bond Enthalpy } \\
(\mathrm{kJ} / \mathrm{mol})^{a}\end{array}$ \\
\hline$\alpha$-Iron & 55.85 & 7.87 & $\mathrm{BCC}$ & 2.8663 & 9.87 & $\begin{array}{c}4.81 \\
(111)^{b}\end{array}$ & $\begin{array}{c}-0.44 \\
\left(\mathrm{Fe}^{2+} / \mathrm{Fe}^{0}\right)^{c}\end{array}$ & $\begin{array}{c}260 \\
(111)^{b}\end{array}$ \\
\hline Copper & 63.55 & 8.96 & FCC & 3.6146 & 1.712 & $\begin{array}{c}4.94 \\
(111)\end{array}$ & $\begin{array}{c}0.340 \\
\left(\mathrm{Cu}^{2+} / \mathrm{Cu}^{0}\right)\end{array}$ & $\begin{array}{l}236 \\
(311)\end{array}$ \\
\hline Nickel & 58.69 & 8.90 & FCC & 3.5241 & 7.12 & $\begin{array}{l}5.35 \\
(111)\end{array}$ & $\begin{array}{c}-0.257 \\
\left(\mathrm{Ni}^{2+} / \mathrm{Ni}^{0}\right)\end{array}$ & $\begin{array}{c}264 \\
(111)\end{array}$ \\
\hline Palladium & 106.42 & 12.0 & FCC & 3.8898 & 10.73 & $\begin{array}{c}5.6 \\
(111)\end{array}$ & $\begin{array}{c}0.915 \\
\left(\mathrm{Pd}^{2+} / \mathrm{Pd}^{0}\right)\end{array}$ & $\begin{array}{l}260 \\
(111)\end{array}$ \\
\hline Platinum & 195.08 & 21.5 & FCC & 3.9231 & 10.7 & $\begin{array}{l}5.93 \\
(111)\end{array}$ & $\begin{array}{c}1.188 \\
\left(\mathrm{Pt}^{2+} / \mathrm{Pt}^{0}\right)\end{array}$ & $\begin{array}{l}255 \\
(111)\end{array}$ \\
\hline Gold & 196.97 & 19.3 & FCC & 4.0782 & 2.255 & $\begin{array}{c}5.31 \\
(111)\end{array}$ & $\begin{array}{c}1.83 \\
\left(\mathrm{Au}^{+} / \mathrm{Au}^{0}\right)\end{array}$ & $\mathrm{NA}^{d}$ \\
\hline Cobalt & 58.93 & 8.86 & $\mathrm{HCP}$ & $\begin{array}{l}a=2.5071 \\
c=4.0686\end{array}$ & $\mathrm{NA}^{e}$ & $\begin{array}{c}5 \\
\text { (polycr) }^{f}\end{array}$ & $\begin{array}{c}-0.277 \\
\left(\mathrm{Co}^{2+} / \mathrm{Co}^{0}\right)\end{array}$ & $\mathrm{NA}^{d}$ \\
\hline
\end{tabular}

${ }^{a}$ Values obtained from ref 6

${ }^{b}$ Crystal face on which value was experimentally determined

${ }^{c}$ Standard reduction potential for the reaction $\mathrm{M}^{\mathrm{n}+}+\mathrm{ne}^{-} \rightarrow \mathrm{M}^{0}$, where value of $\mathrm{M}^{\mathrm{n}+}$ in parentheses

${ }^{d}$ Value not provided in ref 6

${ }^{e}$ Value not provide in ref 5

${ }^{f}$ Value determined on polycrystalline sample 
Table S-3: Values of the relative partial molar enthalpy for an infinitely dilute solution of hydrogen in each metal additive $\left(\Delta \mathrm{H}_{\mathrm{H}}{ }^{\circ}\right)$ taken from Gallagher and Oates (4). Also included are the temperature ranges provided in ref 4 over which each enthalpy value was determined experimentally.

\begin{tabular}{lcc}
\hline \hline \multicolumn{1}{c}{ Metal } & $\begin{array}{c}\Delta \mathbf{H}_{\mathbf{H}}{ }^{\infty} \\
(\mathbf{k c a l} / \mathbf{g}-\mathbf{a t o m} \mathbf{H})\end{array}$ & $\begin{array}{c}\text { Temperature Range } \\
\left({ }^{\circ} \mathbf{C}\right)\end{array}$ \\
\hline$\alpha$-Iron & +6.30 & $300-920$ \\
Copper & +9.46 & $400-1100$ \\
Nickel & +3.87 & $200-1400$ \\
Palladium & -2.39 & $0-300$ \\
Platinum & +18.70 & $1030-1340$ \\
Gold & +8.61 & $700-1000$ \\
Cobalt & +8.69 & $600-1200$ \\
\hline \hline
\end{tabular}




\section{Product Partitioning in Bimetallic Reductant Batch Systems}

Results of nonlinear least squares regression analyses performed on reaction time course data are shown as dashed lines in Figure S-8. Data are shown for an Au/Fe (Figure S-8a) and an $\mathrm{Pd} / \mathrm{Fe}$ (Figure $\mathrm{S}-8 \mathrm{~b}$ ) reductant. These calculations assumed that 1,1,1-TCA reduction occurred via parallel reaction pathways to four groups of products according to Scheme S-1. The term UN was included so that system mass balance was maintained. As is seen in Figure S-8, this approach generally produced model fits that agreed very well with our experimental time course data. We note that the relative ratios of the four product species' concentrations were nearly constant over time.

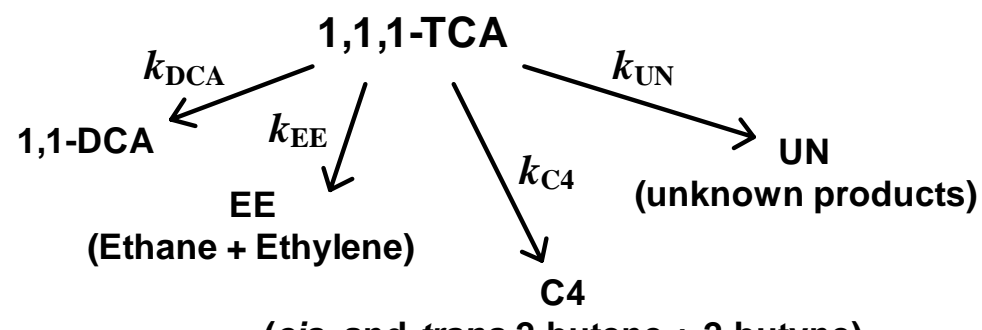

(cis- and trans-2-butene + 2-butyne) Scheme S-1

Rate constants for the formation of 1,1-DCA $\left(k_{\mathrm{DCA}}\right)$ and the sum of ethane and ethylene $\left(k_{\mathrm{EE}}\right)$ are shown in Figure S-9. For the rate-enhancing additives (shown as Figures S-9a through S-9d), both $k_{\mathrm{EE}}$ and $k_{\mathrm{DCA}}$ were generally greater than that measured with unamended iron (values of $k_{\mathrm{EE}}$ and $k_{\mathrm{DCA}}$ measured in an unamended iron system are shown as dashed horizontal lines in Figure S-9), and tended to increase with additive loading. Consequently, these reductants produced ethane, ethylene and 1,1-DCA at a greater rate relative to unamended iron. In most cases, however, the rate of increase of $k_{\mathrm{EE}}$ was far greater than that of $k_{\mathrm{DCA}}$ over the additive loadings considered. For example, over the range of Ni loadings investigated we observed as much as a 15 -fold increase in $k_{\mathrm{EE}}$ compared to only a 2 -fold increase in $k_{\mathrm{DCA}}$. We note that the 
maximum increase in $k_{\text {obs }}$ for 1,1,1-TCA reduction measured in $\mathrm{Ni} / \mathrm{Fe}$ systems was approximately eight-fold.

Interestingly, $\mathrm{Pd} / \mathrm{Fe}$ systems (Figure $\mathrm{S}-9 \mathrm{~b}$ ) displayed slightly different trends in product formation rate constants than the other rate-enhancing bimetals (i.e., $\mathrm{Ni} / \mathrm{Fe}, \mathrm{Cu} / \mathrm{Fe}$ and $\mathrm{Co} / \mathrm{Fe}$ ). While $k_{\mathrm{EE}}$ values increased considerably with increasing Pd loading, values of $k_{\mathrm{DCA}}$ were invariant. Thus, the rate of 1,1-DCA production was identical in both unamended iron and $\mathrm{Pd} / \mathrm{Fe}$ systems, suggesting that the ability of $\mathrm{Pd} / \mathrm{Fe}$ to enhance the rate of $1,1,1-\mathrm{TCA}$ reduction may be entirely related to the reduction pathway that yields ethane and ethylene.

In Pt/Fe and $\mathrm{Au} / \mathrm{Fe}$ systems (Figure S-9e and S-9f), values of $k_{\mathrm{DCA}}$ were less than that observed in unamended iron systems and progressively decreased with increasing additive loading. On the other hand, values of $k_{\mathrm{EE}}$ for $\mathrm{Pt} / \mathrm{Fe}$ and $\mathrm{Au} / \mathrm{Fe}$ reductants were either greater than or equal to the value of $k_{\mathrm{EE}}$ in unamended iron systems. Thus, even though these metal additives exerted no positive influence on $k_{\mathrm{obs}}$ values for 1,1,1-TCA reduction, they were still capable of influencing 1,1,1-TCA product partitioning. It is interesting to note that $k_{\mathrm{EE}}$ was enhanced more in the $\mathrm{Au} / \mathrm{Fe}$ system than in the $\mathrm{Pt} / \mathrm{Fe}$ system; this may reflect differences in the solubility of atomic hydrogen within these two additives.

For all bimetallic reductants, differences in the rate and magnitude of change in $k_{\mathrm{DCA}}$ relative to $k_{\mathrm{EE}}$ indicate that the yield of each product must change as additive loading is increased. The yield of each reduction product, defined as $\frac{k_{\mathrm{i}}}{k_{\mathrm{obs}}}$ where $i=\mathrm{DCA}, \mathrm{EE}$ or $\mathrm{C} 4$ and $k_{\text {obs }}$ is the pseudo-first-order rate constant for 1,1,1-TCA reduction, is shown in Figure S-10 for each bimetallic system. In all systems, the yield of 1,1-DCA was depressed relative to unamended iron systems (yields measured in unamended iron systems are shown as dashed horizontal lines). In contrast, each bimetal increased the yield of the sum of ethane and ethylene 
relative to unamended iron. As independent experiments found 1,1-DCA to be unreactive in all reductant systems, changes in the relative yield of 1,1-DCA, ethane and ethylene are indicative of a shift in the relative importance of the step(s) governing the partitioning between ethane plus ethylene versus 1,1-DCA.

Finally, we note that the yield of coupling products was generally similar in both unamended iron and bimetallic reductant systems. The yield of coupling products did increase by a statistically significant margin in $\mathrm{Au} / \mathrm{Fe}$ systems, however, while in $\mathrm{Pd} / \mathrm{Fe}$ systems, it clearly decreases with increasing Pd loading. 

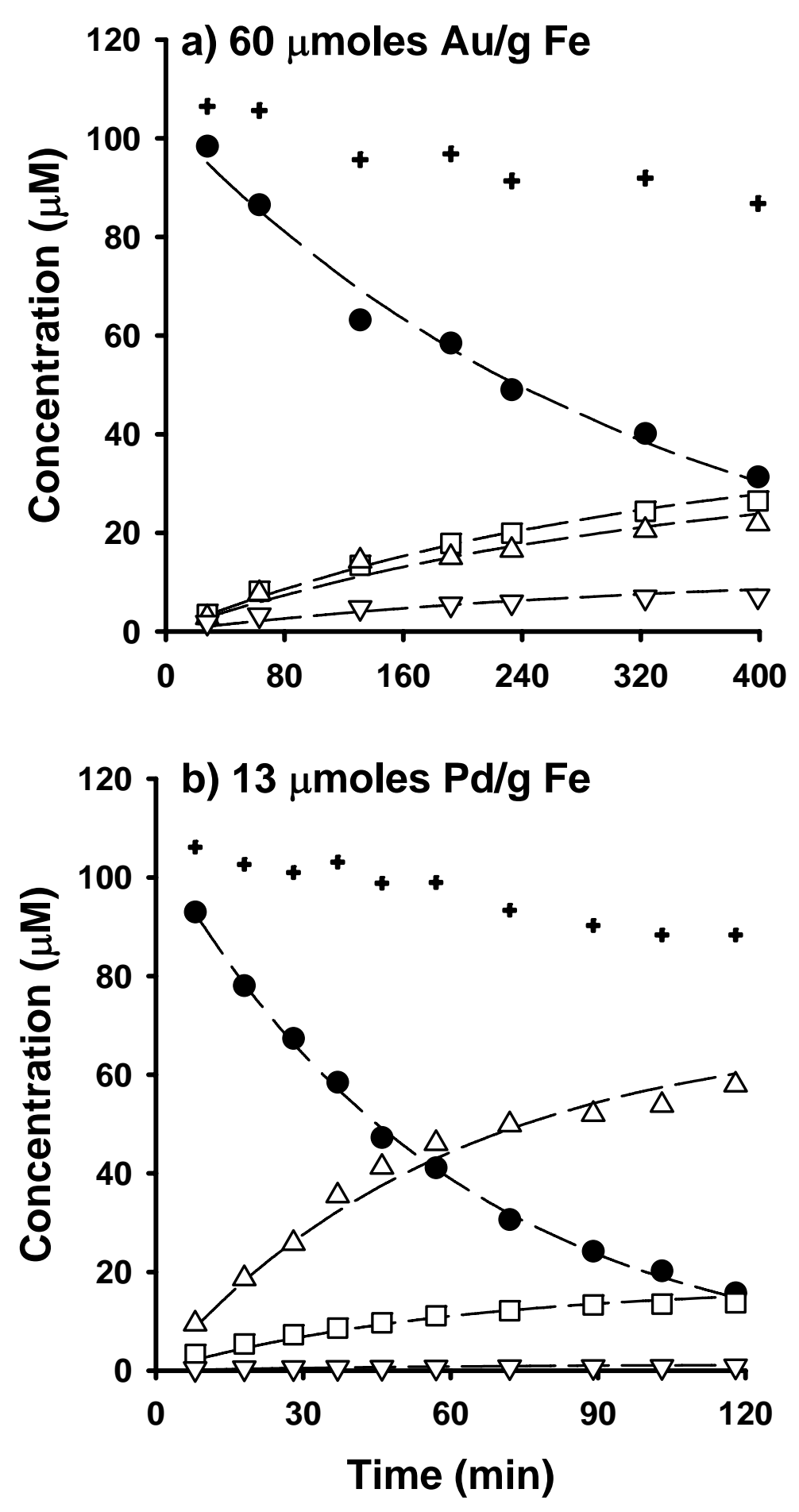

Figure S-8: Reaction time courses obtained with (a) $\mathrm{Au} / \mathrm{Fe}(60 \mu$ moles $\mathrm{Au} / \mathrm{g} \mathrm{Fe})$ and (b) $\mathrm{Pd} / \mathrm{Fe}$ (13 $\mu$ moles $\mathrm{Pd} / \mathrm{g} \mathrm{Fe}$ ) reductants. Dashed lines represent nonlinear least squares regression fits to experimental data. Concentration data as a function of time are shown for 1,1,1-TCA $(\bullet)$, the sum of ethane and ethylene $(\Delta), 1,1-\mathrm{DCA}(\square), \mathrm{C} 4$ coupling products $(\nabla)$ and system carbon mass balance $(+)$. Batch reactors contained $50 \mathrm{mM}$ Tris $/ 0.1 \mathrm{M} \mathrm{NaCl}$ at an initial $\mathrm{pH}$ of 7.20 and a bimetallic reductant loading of $1.6 \mathrm{~g} / \mathrm{L}$. 
a) $\mathrm{Ni} / \mathrm{Fe}$

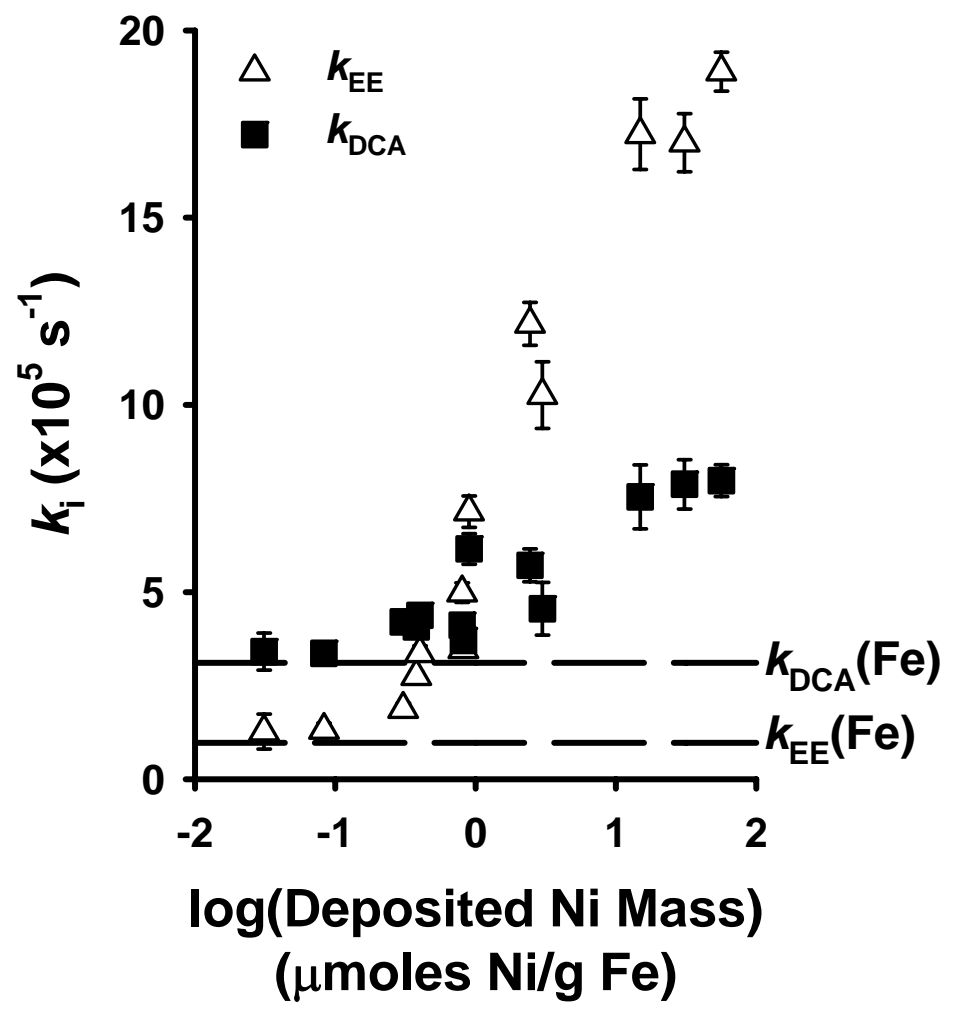

c) $\mathrm{Cu} / \mathrm{Fe}$

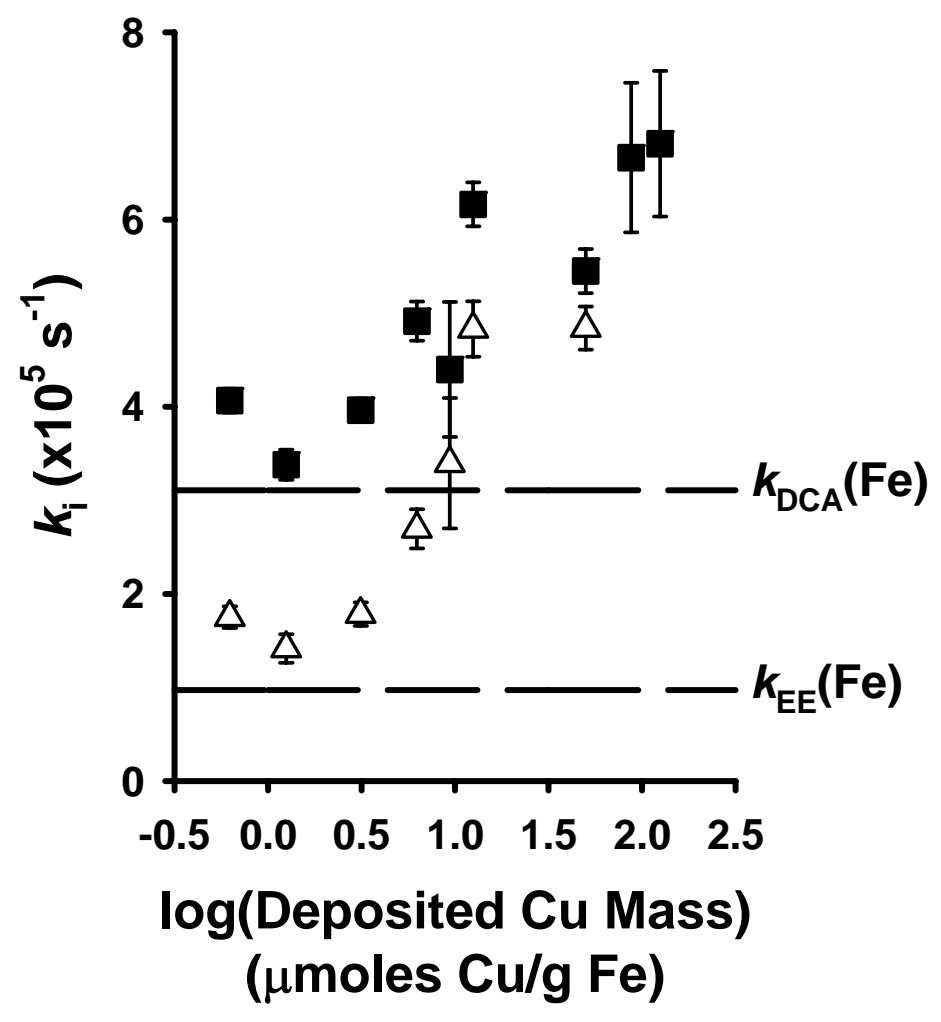

b) $\mathrm{Pd} / \mathrm{Fe}$

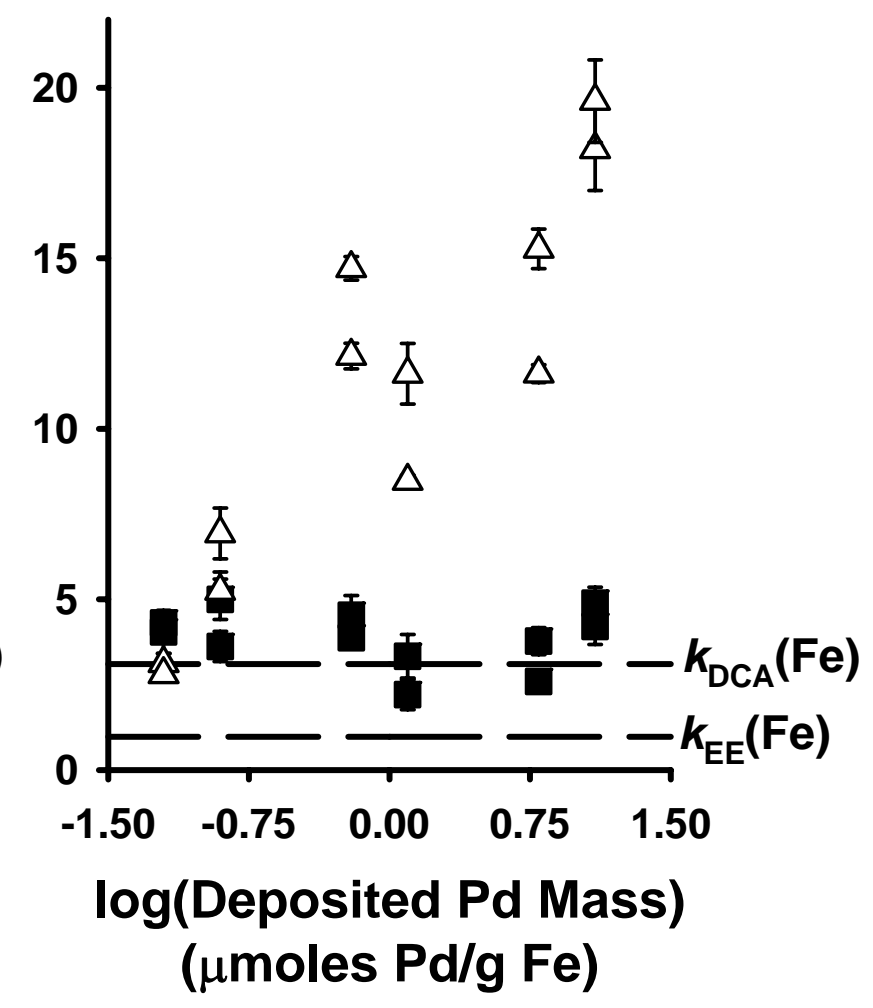

d) $\mathrm{Co} / \mathrm{Fe}$

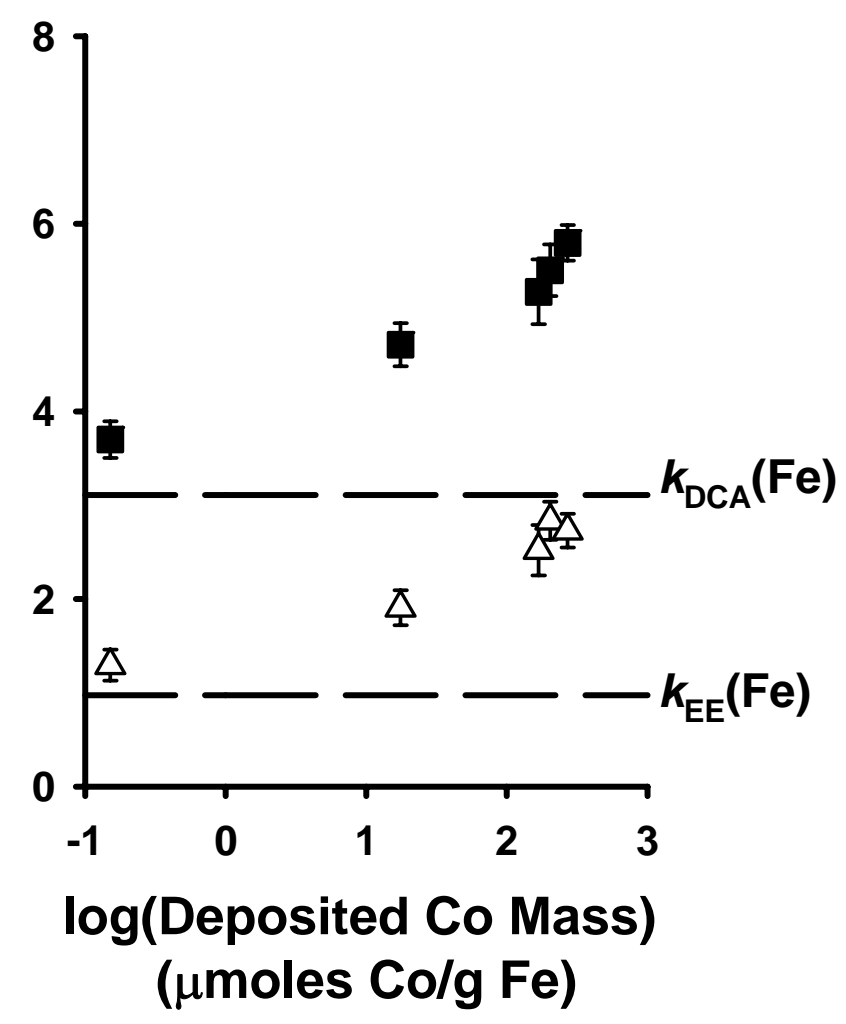


e) Au/Fe

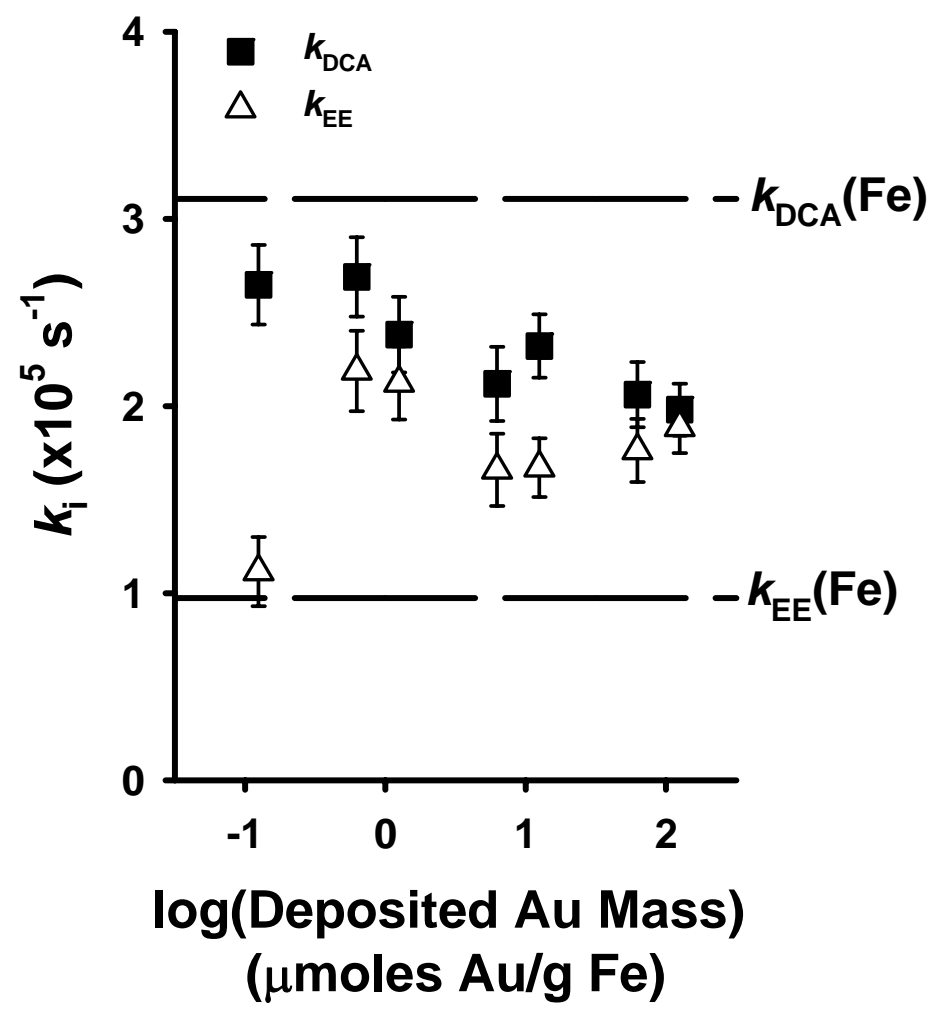

\section{f) $\mathrm{Pt} / \mathrm{Fe}$}

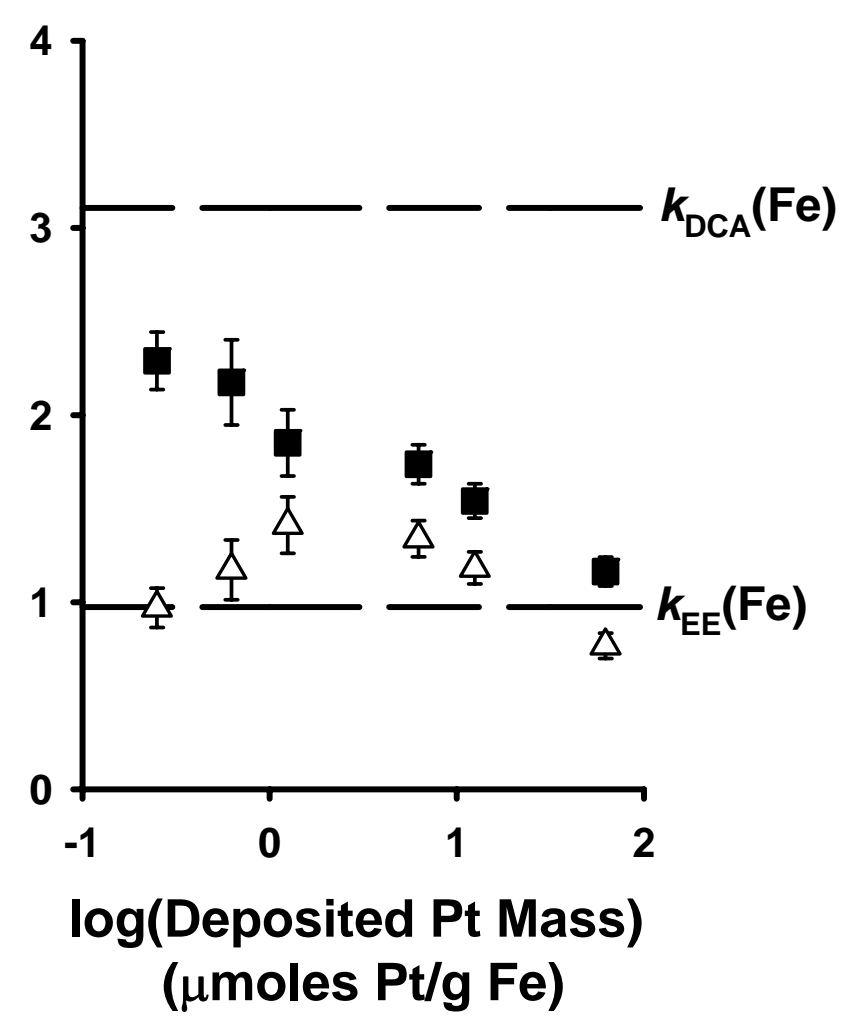

Figure S-9: Rate constants for the formation of 1,1-DCA $\left(k_{\mathrm{DCA}}\right)$ and the sum of ethane and ethylene ( $k_{\mathrm{EE}}$ ) in (a) $\mathrm{Ni} / \mathrm{Fe}$, (b) $\mathrm{Pd} / \mathrm{Fe}$, (c) $\mathrm{Cu} / \mathrm{Fe}$, (d) $\mathrm{Co} / \mathrm{Fe}$, (e) $\mathrm{Au} / \mathrm{Fe}$ and (f) $\mathrm{Pt} / \mathrm{Fe}$ reductant systems. Values were obtained from nonlinear regression analyses of experimental time course data and are shown as a function of deposited additive mass on a logarithmic scale. Dashed horizontal lines represent the corresponding values for product formation rate constants measured in an unamended iron system $\left(k_{\mathrm{DCA}}(\mathrm{Fe})=3.1( \pm 0.15) \times 10^{-5} \mathrm{~s}^{-1}\right.$ and $k_{\mathrm{EE}}(\mathrm{Fe})=0.97( \pm$ $\left.0.12) \times 10^{-5} \mathrm{~s}^{-1}\right)$. Uncertainties represent $95 \%$ confidence intervals. 
a) $\mathrm{Ni} / \mathrm{Fe}$

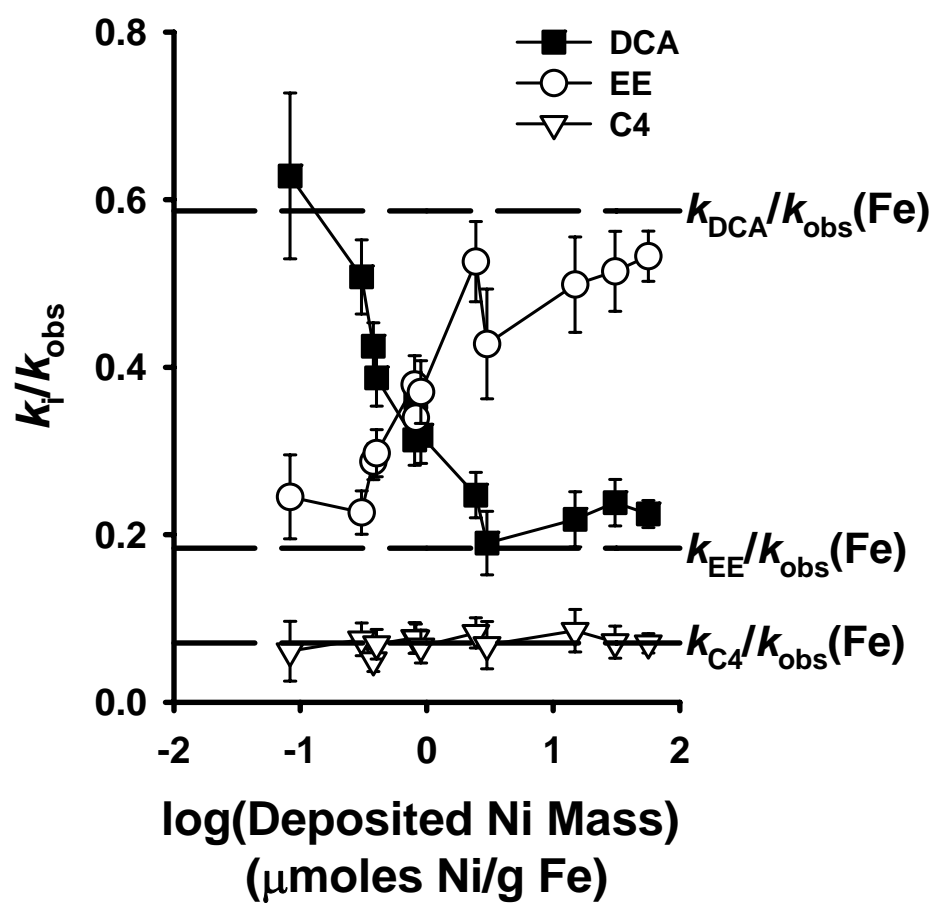

b) $\mathrm{Pd} / \mathrm{Fe}$

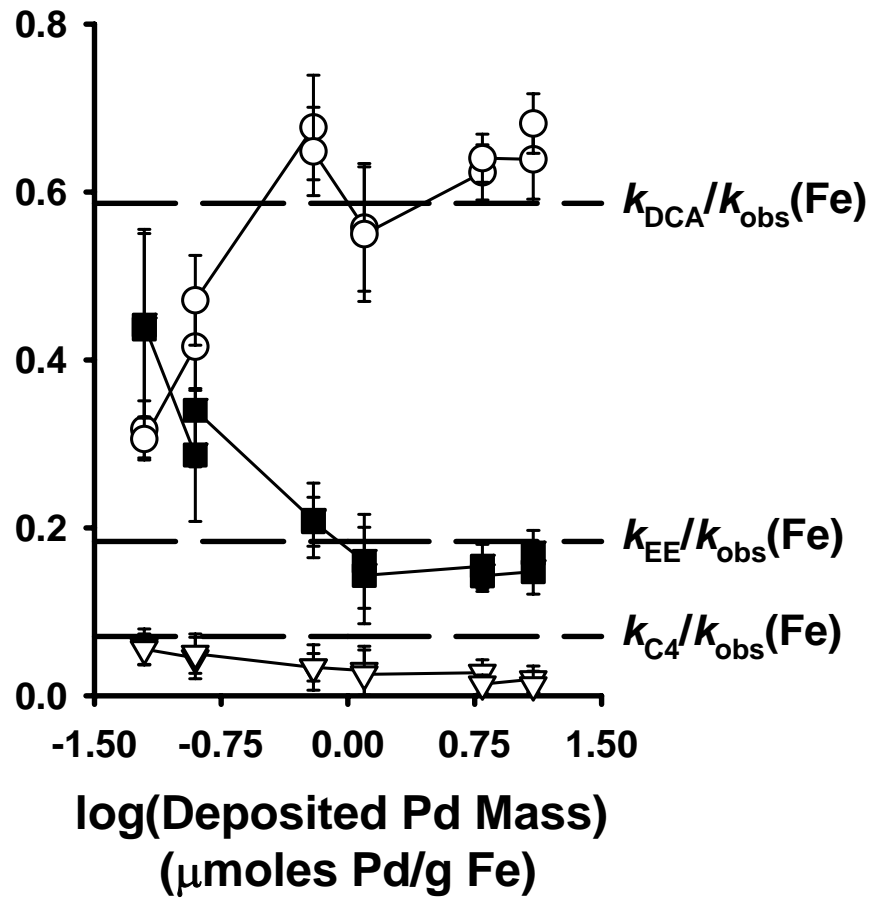

c) $\mathrm{Cu} / \mathrm{Fe}$

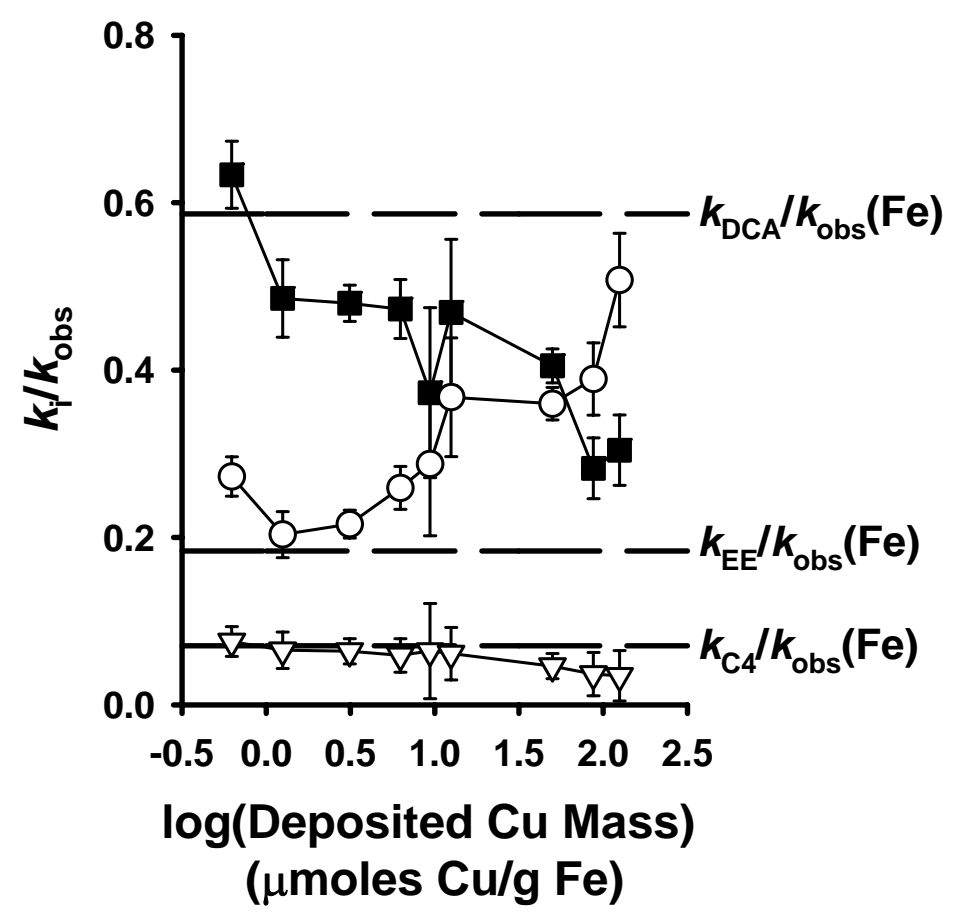

d) $\mathrm{Co} / \mathrm{Fe}$

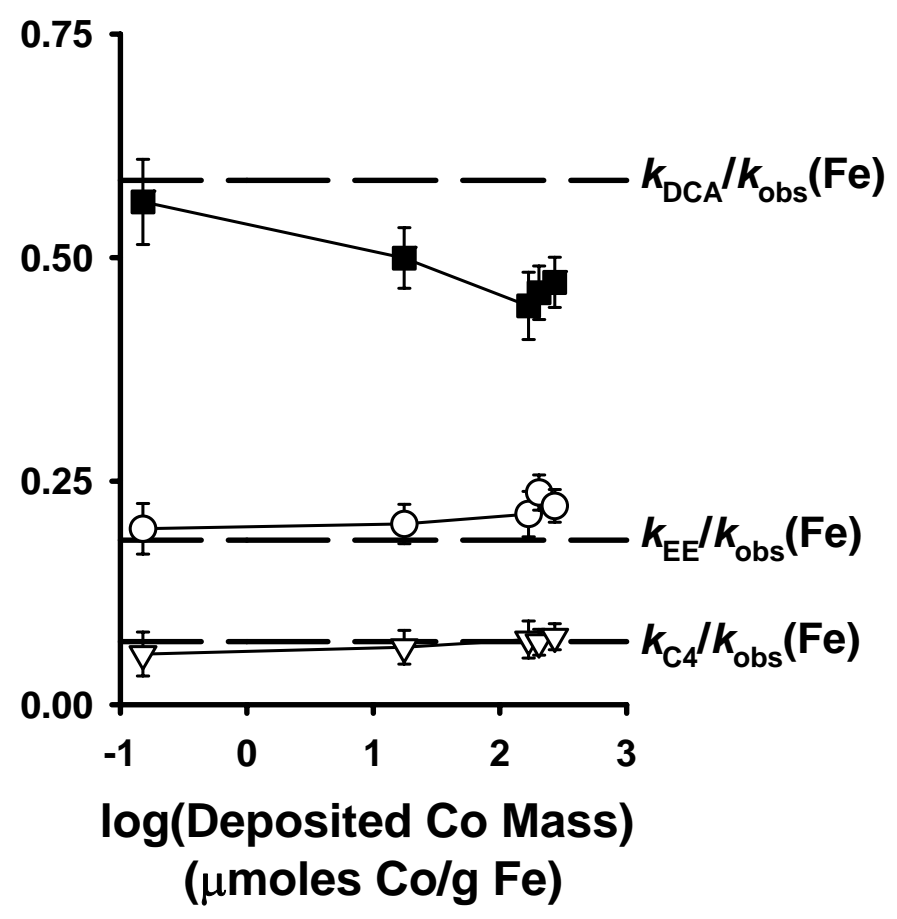




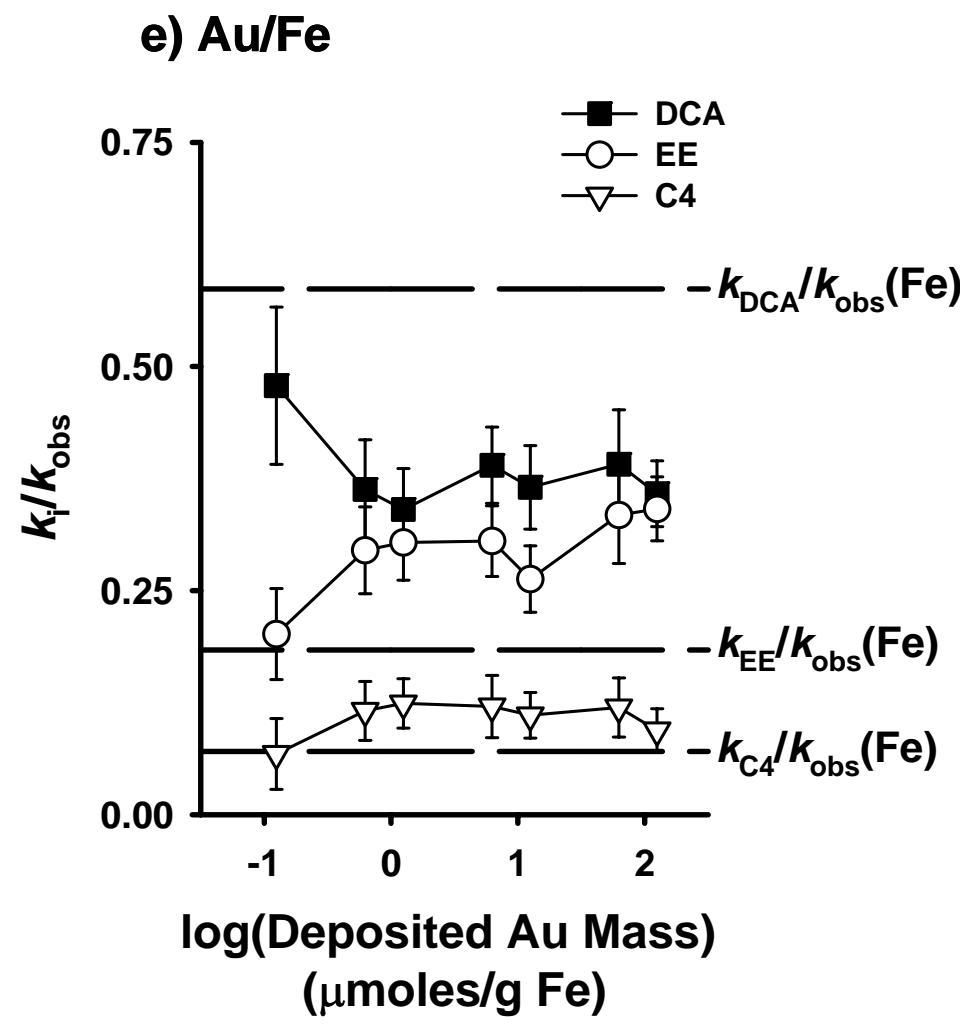

\section{f) $\mathrm{Pt} / \mathrm{Fe}$}

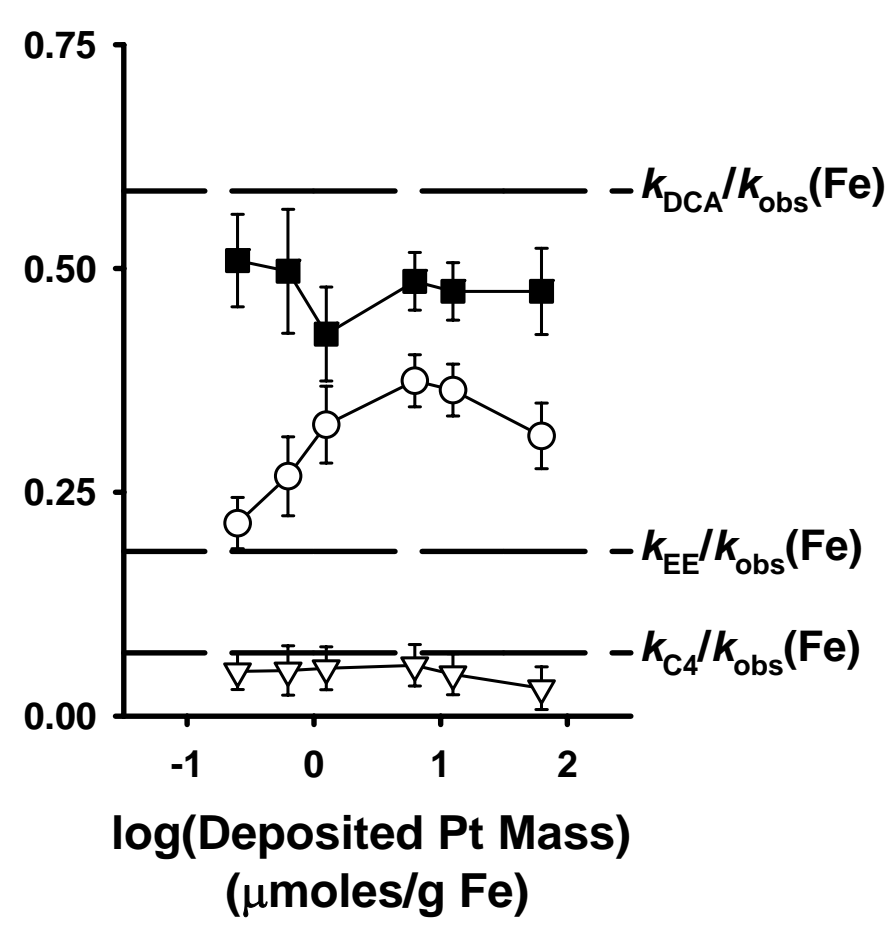

Figure S-10: Product yields for the formation of 1,1-DCA, the sum of ethane and ethylene, and C4 coupling products in (a) $\mathrm{Ni} / \mathrm{Fe}$, (b) $\mathrm{Pd} / \mathrm{Fe}$, (c) $\mathrm{Cu} / \mathrm{Fe}$, (d) $\mathrm{Co} / \mathrm{Fe}$, (e) $\mathrm{Au} / \mathrm{Fe}$ and (f) $\mathrm{Pt} / \mathrm{Fe}$ reductant systems. Values are shown as a function of deposited additive mass on a logarithmic scale. Dashed horizontal lines represent the corresponding product yields measured in an unamended iron system $\left(k_{\mathrm{DCA}} / k_{\mathrm{obs}}(\mathrm{Fe})=0.59 \pm 0.06, k_{\mathrm{EE}} / k_{\mathrm{obs}}(\mathrm{Fe})=0.18 \pm 0.03\right.$ and $k_{\mathrm{C} 4} / k_{\mathrm{obs}}=$ $0.07 \pm 0.02)$. Uncertainties represent $95 \%$ confidence intervals. 


\section{Literature Cited}

(1) Bransfield, S. J.; Cwiertny, D. M.; Roberts, A. L.; Fairbrother, D. H. Influence of Cu loading and surface coverage on the reactivity of granular iron toward 1,1,1trichloroethane. Environ. Sci. Technol. 2006, 40, 1485-1490.

(2) Matheson, L. J.; Tratnyek, P. G. Reductive dehalogenation of chlorinated methanes by iron metal. Environ. Sci. Technol. 1994, 28, 2045-2053.

(3) Cwiertny, D. M.; Roberts, A. L. On the nonlinear relationship between $k_{\text {obs }}$ and reductant mass loading in iron batch systems. Environ. Sci. Technol. 2005, 39, 8948-8957.

(4) Gallagher, P. T.; Oates, W. A. Partial excess entropies of hydrogen in metals. Trans. Metall. Soc. AIME 1969, 245, 179-182.

(5) CRC, Handbook of Chemistry and Physics; 84th ed.; CRC Press: Cleveland, 2004.

(6) Christmann, K. R. Hydrogen Sorption on Pure Metal Surfaces. In Hydrogen Effects in Catalysis Fundamentals and Practical Applications; Paal, Z., Menon, P. G., Eds.; Marcel Dekker: New York, 1988; pp 3-55. 